\title{
DIFERENCIAS TERRITORIALES EN EL CONCEPTO DE \\ COOPERATIVA PROTEGIDA Y ESPECIALMENTE PROTEGIDA ${ }^{1}$
}

\author{
POR \\ Pilar ALGUACIL MARÍ ${ }^{2}$ y \\ Agustín ROMERO CIVERA ${ }^{3}$
}

\section{RESUMEN}

Tras diversos estudios sobre las divergencias territoriales en materia de impacto fiscal que produce la aplicación de la legislación fiscal (ley 20/90) en las cooperativas españolas al conjugarse con una legislación sustantiva autonómica diversa, nos hemos planteado solo investigar en los requisitos para su aplicación.

Estos requisitos, planteados en los artículos 6 y 13, remiten a la ley sustantiva, con importantes turbulencias y algunas diferencias importantes en la tributación, que permiten plantearse una mayor homogeneización futura en aras a una equidad legislativa.

Incluso para la aplicación del régimen especial, los requisitos planteados en los artículos 8 al 12, aunque son independientes de la legislación sustantiva, son claramente obsoletos.

\footnotetext{
${ }^{1}$ El presente artículo constituye un resultado del proyecto de investigación financiado por el Ministerio de Ciencia e Innovación con título LAS POLITICAS PUBLICAS EN EL TRATAMIENTO FISCAL Y DE AYUDAS PUBLICAS A LAS ENTIDADES DE LA ECONOMIA SOCIAL y referencia DER2009-14462-C0201.

${ }^{2}$ Pilar ALGUACIL MARÍ: Catedrática de Derecho Financiero y Tributario, miembro del Instituto Universitario de investigación en Economía Social y cooperativa (Iudescoop), Universidad de Valencia. Campus de Tarongers, Edificio Occidental, 2 B06, 46022 Valencia (Spain), teléfono 0034961625290 fax 0034963828583. Dirección de correo electrónico: alguacil@uv.es

${ }^{3}$ Agustín ROMERO CIVERA: Profesor contratado doctor en la Universidad Politécnica de Valencia. Departamento de Economía y Ciencias Sociales- Miembro del Centro de Estudios en Gestión de Empresas $\left(\right.$ CEGEA $\left.^{3}\right) . \mathrm{C}^{\circ}$ de Vera s/n 46022 Valencia (Spain). Dirección de correo electrónico: aromero@ cegea.upv.es
}

REVESCO No 110 - Primer Cuatrimestre 2013 - ISSN: 1885-8031 - www.ucm.es/info/revesco

http://dx.doi.org/10.5209/rev_REVE.2013.v110.41446

Fecha de recepción: 19/09/2011

Fecha de aceptación: 30/10/2012 
Se analizan las enormes diferencias legislativas, cuantificando la presión fiscal de las mismas, en lo posible, y se destacan las similitudes, concordancias e incongruencias entre las diferentes legislaciones con resultados sorprendentes en algunos casos.

Palabras clave: Legislación fiscal, Impacto fiscal, Cooperativas, Legislación Autonómica, Requisitos económicos

Claves Econlit: K340: Tax Law. L390: Nonprofit Organizations and Public Enterprise: Other. H220 - Taxation and Subsidies: Incidence

\title{
REGIONAL DIFFERENCES IN THE CONCEPT OF PROTECTED COOPERATIVE AND SPECIALLY PROTECTED COOPERATIVE
}

\begin{abstract}
Following several studies on regional differences in fiscal impact produced by the application of tax law (Law 20/90) in Spanish cooperatives because of the existence of very different substantive regional law, we have considered to investigate only the requirements for the application of the special tax regime.
\end{abstract}

These requirements, as set forth in Articles 6 and 13, refer to the substantive law, with significant turbulence and some important differences in taxation. So it would be convenient to consider to improve greater homogenization in future legislative for equity's sake.

Even for the more special scheme, the requirements set out in Articles 8 to 12, that are in a greater degree independent of the substantive law, are clearly outdated.

The paper discusses the huge differences in legislation, quantifying the tax burden of it, when possible, and highlights the similarities, commonalities and inconsistencies between different laws with surprising results in some cases.

Keywords: Tax legislation, fiscal impact, cooperatives, regional legislation, economic requirements 


\section{INTRODUCCIÓN}

El régimen fiscal de cooperativas es objeto, en la actualidad, de una profunda reflexión - entre los estudiosos del tema, pero asimismo, desde el mismo sector - acerca de la necesidad o la conveniencia de una reforma, así como de la intensidad de la misma.

Pues bien, en el presente trabajo hemos intentado determinar si se ajusta a la realidad la crítica, tantas veces repetida, de que las divergencias en la normativa sustantiva determinan un tratamiento diferenciado en el ámbito fiscal. (Juliá y otros, 1999) (Gallego, 2002). Para ello nos hemos centrado en uno de los primeros aspectos de dicho régimen: los requisitos para su aplicación, que de alguna forma configurarían el modelo de cooperativa que se entiende merecedora de un régimen fiscal especial.

Quizá la primera cuestión que se plantea en relación con los requisitos para un régimen fiscal de una concreta figura societaria, desde nuestro punto de vista, sea la de si los mismos deben configurar un régimen propio, o si deben limitarse a homologar de una forma directa o indirecta, el cumplimiento de los elementos del régimen sustantivo de dicha Entidad jurídica.

En nuestra opinión, el régimen actualmente recogido en la ley 20/1990, de 19 de diciembre, de régimen fiscal de Cooperativas, (en adelante LFC) no hace ni una cosa ni otra, especialmente en cuanto a los requisitos para las cooperativas protegidas, no establece criterios propios para asegurar la uniformidad de trato fiscal y el cumplimiento del principio de igualdad; criterios basados en principios específicamente tributarios, sino que se limita, en general, a "homologar" el régimen sustantivo. Sin embargo, dicho régimen sustantivo puede resultar muy variado, ya que, como es sabido, las CCAA han hecho uso de sus competencias normativas en la materia.

En general, el art. 13, al regular las causas de pérdida de la condición de cooperativa protegida, remite a la legislación sustantiva; si bien en esta homologación causa turbulencias con dicho régimen mercantil, porque aunque en ocasiones remite directamente a la regulación sustantiva, en otras realiza su propia versión de las características que deben ornar a la cooperativa. Con lo que se producen, no sólo desigualdades de trato, sino asimismo incoherencias dentro del propio texto legal en relación con otros aspectos del régimen fiscal. 
En cambio, en los artículos 8 y ss., cuando se enumeran aquellos necesarios para la especial protección, la ley establece de forma autónoma sus requisitos. Estos requisitos, como veremos, están parcialmente inspirados en los que definían a las figuras cooperativas en la ley General de cooperativas, y por ello generan bastante confusión con los actualmente regulados en las leyes estatal y autonómicas para las concretas cooperativas afectadas.

\section{LOS REQUISITOS EN LA LEY DE RÉGIMEN FISCAL DE COOPERATIVAS PARA LA PROTECCIÓN FISCAL}

En la actualidad, dichos requisitos se contemplan en los artículos 6 y 13-14 de la LFC. Podemos distinguir entre los requisitos para la aplicación de las normas de ajuste, y aquellos referidos al régimen de protección fiscal (Alguacil, 2001).

En cuanto a los requisitos para la aplicación de las normas de ajuste, en el 6.2 se establece que en todo caso, las normas de ajuste se aplicarían "a todas las cooperativas regularmente constituidas e inscritas en el Registro de cooperativas correspondiente".

Adicionalmente a estos requisitos, para que la cooperativa sea considerada protegida, debe cumplir lo dispuesto en el art. 6.1 de la ley y no incurrir en una "causa de pérdida de la condición" de las previstas en el art. 13 de la misma.

En el artículo 6.1, se efectúa una remisión genérica al cumplimiento de la normativa sustantiva que le sea de aplicación4. Esta previsión genera dos efectos indeseados:

En primer lugar, una considerable incertidumbre jurídica, que supone, además, una potencial causa de conflictos con la Inspección tributaria, quien, tomando el texto en su literalidad, podría aducir como causa de pérdida de la protección fiscal cualquier incumplimiento de la normativa sustantiva, por nimio que éste fuera

En segundo lugar, el resultado puede ser muy injusto, por dos razones: la primera, por la enorme variedad legislativa que existe en nuestro país en materia de cooperativas. La segunda, por la distinta incidencia que puede tener en la justificación de la no aplicación del régimen la naturaleza concreta del incumplimiento de la normativa cooperativa. Esto es, no

\footnotetext{
${ }^{4}$ Literalmente, que “....se ajusten a los principios y disposiciones de la Ley General de cooperativas o de las Leyes de cooperativas de las Comunidades autónomas que tengan competencia en esta materia...”. Obviamente, la referencia a la Ley General debe entenderse realizada en la actualidad a la ley estatal 27/1999 de cooperativas.
} 
cualquier incumplimiento de la normativa cooperativa debería generar el efecto de pérdida del régimen fiscal, sino que dicho incumplimiento debería ser de tal naturaleza que "desnaturalizara" a la cooperativa, eliminando la razón que justifica que se le aplique un tratamiento especial respecto del resto de sociedades. Y debería elegirse un elemento que dotara de seguridad jurídica suficiente la aplicación del régimen, como por ejemplo, haber sido objeto de descalificación.

Los motivos de descalificación contemplados en las leyes autonómicas suelen ser los mismos, aunque en los casos de Asturias, Galicia, País Vasco y Murcia, se considera tal la "pérdida o incumplimiento de los requisitos necesarios para la calificación” de modo genérico, en el resto se detallan mucho más los motivos, que suelen incluir los motivos de disolución que figuran en las 8 primeras columnas de la tabal 1, pero, eso sí con grandes divergencias de criterio. Finalmente aparece siempre como motivo de descalificación la existencia de infracciones, pero no es unánime la consideración de si han de ser muy graves, solo graves, con o sin reincidencia, o con o sin grave perjuicio económico. Andalucía también incluye el "mal uso" del término "cooperativa, con fines ajenos a este tipo de entidades". 
Tabla 1. Causas de descalificación en las distintas leyes cooperativas.

\begin{tabular}{|c|c|c|c|c|c|c|c|c|c|c|c|}
\hline $\begin{array}{l}\text { causas de } \\
\text { descalificación }\end{array}$ & $\begin{array}{l}\text { cumplimiento } \\
\text { del término } \\
\text { fijado en los } \\
\text { estatutos } \\
\text { sociales }\end{array}$ & \begin{tabular}{|c|} 
conclusión de la \\
empresa que \\
constituye su \\
objeto o la \\
imposibilidad de \\
realizar la \\
actividad \\
cooperativizada \\
\end{tabular} & $\begin{array}{c}\text { La voluntad } \\
\text { de los socios, } \\
\text { manifestada } \\
\text { mediante } \\
\text { acuerdo de } \\
\text { asamblea } \\
\text { general } \\
\end{array}$ & $\begin{array}{c}\text { La reducción } \\
\text { del número } \\
\text { de socios por } \\
\text { debajo del } \\
\text { mínimo legal }\end{array}$ & $\begin{array}{c}\text { La reducción } \\
\text { de la cifra del } \\
\text { capital social } \\
\text { por debajo del } \\
\text { mínimo } \\
\text { establecido en } \\
\text { estatutos }\end{array}$ & $\begin{array}{c}\text { La fusión } \\
\text { y la } \\
\text { escisión }\end{array}$ & $\begin{array}{c}\text { la } \\
\text { quiebra }\end{array}$ & $\begin{array}{c}\text { la } \\
\text { inactividad } \\
\text { de la } \\
\text { cooperativ } \\
\text { a o de susu } \\
\text { organos } \\
\text { sociales }\end{array}$ & \begin{tabular}{|} 
cuando existan \\
infraccionas graves \\
o muy graves, \\
susceptibres de \\
grandes perjuicios \\
económicos o \\
reincidencia
\end{tabular} & Artículo & $\begin{array}{c}\text { Ley } \\
\text { CCAA }\end{array}$ \\
\hline ANDALUCIA & no & si & no & si & si & si & si & si & si & 110 y 170 & L 2/1999 \\
\hline ARAGON & si & si & si & si & si & \begin{tabular}{|c|}
$\mathrm{si}, \mathrm{y}$ \\
transform \\
ación
\end{tabular} & si & si & $\begin{array}{c}\text { muy graves o } \\
\text { reincidencia } \\
\text { incumplimiento ley }\end{array}$ & 67 y 95 & L 9/1998 \\
\hline ASTURIAS & \multicolumn{8}{|c|}{ pérdida o incumplimiento de los requisitos necesarios para la calificación } & solo muy graves & 208 y 117 & L 4/2010 \\
\hline BALEARES & no & si & no & si & si & no & si & si & $\begin{array}{c}\text { muy graves, } \\
\text { reinicedencia o/y } \\
\text { perjuicio }\end{array}$ & 149 y 95 & L $1 / 2003$ \\
\hline $\begin{array}{c}\text { CASTILLA LA } \\
\text { MANCHA }\end{array}$ & no & si & no & si & si & no & no & si & $\begin{array}{c}\text { muy graves y } \\
\text { perjuicio }\end{array}$ & 162 y 110 & L $11 / 2010$ \\
\hline CASTILLA LEON & no & si & no & si & si & no & no & si & solo muy graves & 138 y 90 & L 4/2004 \\
\hline CATALUÑA & no & si & no & no & no & no & no & si & solo muy graves & 138 y 86 & L $18 / 2002$ \\
\hline EUSKADI & \multicolumn{8}{|c|}{ pérdida o incumplimiento de los requisitos necesarios para la calificación } & $\begin{array}{c}\text { muy graves, } \\
\text { reinicedencia o/y } \\
\text { perjuicio }\end{array}$ & 141 & L $1 / 2000$ \\
\hline EXTREMADURA & no & si & no & si & si & no & si & si & \begin{tabular}{|c|}
$\begin{array}{c}\text { muy graves o } \\
\text { reincidencia } \\
\text { incumplimiento ley }\end{array}$ \\
\end{tabular} & 180 y 96 & L 2/1998 \\
\hline GALICIA & no & si & no & si & si & no & si & si & $\begin{array}{c}\text { muy graves y } \\
\text { perjuicio }\end{array}$ & 86 y 141 & L 5/1998 \\
\hline LA RIOJA & no & si & no & si & si & no & si & si & solo muy graves & 93 y 142 & $\mathrm{~L} 4 / 2001$ \\
\hline MADRID & no & si & no & si & si & no & si & si & $\begin{array}{c}\text { graves, muy graves } \\
\text { y vulneración } \\
\text { esencial }\end{array}$ & 93 y 135 & L 4/1999 \\
\hline MURCIA & \multicolumn{8}{|c|}{ pérdida o incumplimiento de los requisitos necesarios para la calificación } & $\begin{array}{c}\text { muy graves, } \\
\text { reinicedencia o/y } \\
\text { perjuicio }\end{array}$ & 141 & L 7/2006 \\
\hline NAVARRA & si & no & si & si & si & si & si & no & $\begin{array}{l}\text { incumplimiento } \\
\text { plazo disolución }\end{array}$ & 60 y 62 & LF 14/2006 \\
\hline C. VALENCIANA & no & si & no & no & no & no & no & si & $\begin{array}{c}\text { muy graves o } \\
\text { reincidencia } \\
\text { incumplimiento ley }\end{array}$ & 121 & L $8 / 2003$ \\
\hline LEY ESTATAL & no & si & no & si & si & no & no & si & solo muy graves & 70 y 116 & L 27/1999 \\
\hline
\end{tabular}

Fuente: Elaboración propia

REVESCO No 110 - Primer Cuatrimestre 2013 - ISSN: 1885-8031 - www.ucm.es/info/revesco 


\section{LAS CAUSAS DE PÉRDIDA DE LA PROTECCIÓN FISCAL}

El art. 13 contempla un listado común a todas las cooperativas, no de requisitos, sino de causas de pérdida de la protección fiscal. Ello es coherente con el punto de partida de la ley, en el sentido de que dicha protección se otorga por el mero cumplimiento de la normativa cooperativa aplicable. Sin embargo, es realmente en este precepto donde se dilucidan, aunque sea de esta forma indirecta, los requisitos para que la cooperativa sea merecedora de un régimen fiscal especial. El espíritu era recoger las faltas graves o muy graves de la legislación cooperativa (De Luis, 1991).

Ahora bien, las causas actualmente contempladas en el art. 13 LFC no tienen todas la misma gravedad, desde el punto de vista del régimen sustantivo cooperativo. Asimismo, dado que en el momento de aprobación de la LFC era mayoritariamente aplicada la ley General de Cooperativas de 1987, el redactor de aquella no pareció creer que fuera necesario asegurarse de que en los requisitos establecidos para el régimen fiscal hiciera falta indicar los rasgos básicos y esenciales de la cooperativa, dado que éstos estaban recogidos en la regulación sustantiva. Así, resulta paradigmático que no se recogiera la necesidad del voto democrático, o que una parte, al menos, del capital, fuera variable para permitir el principio de puertas abiertas.

Veamos las causas previstas en dicho precepto, y cómo están recogidas sus remisiones en las leyes cooperativas autonómicas. Dice el citado artículo que "Será causa de pérdida de la condición de cooperativa fiscalmente protegida incurrir en alguna de las circunstancias que se relacionan a continuación", con 16 supuestos que se comentan uno a uno:

1.

"No efectuar las dotaciones al fondo de reserva obligatorio y al de educación y promoción, en los supuestos, condiciones y por la cuantía exigida en las disposiciones cooperativas"

Cada ley autonómica fija diferentes porcentajes de dotación al Fondo de reserva obligatorio, procedentes de los resultados cooperativos, extracooperativos y extraordinarios, produciéndose decenas de diferencias en las cuantías tanto como en los rendimientos sobre los que deben realizarse las dotaciones (Gallego, 2002) Además, la calificación de unos y otros resultados no es coincidente en las distintas legislaciones sustantivas, ni tampoco con los que la LFC califica como tales en los artículos 17 a 22, lo que genera más distorsiones en el cálculo de la Base imponible del impuesto sobre Sociedades. Para empezar, la misma no 
considera de forma independiente los resultados extraordinarios de los extracooperativos, cuya diferenciación de trato es sin embargo bastante frecuente en la normativa autonómica (Juliá y otros, 1999). No obstante, la pérdida de condición de protegida se daría en el caso de no efectuar dichas dotaciones, por lo que en todo caso sólo es obligatorio lo que establezca la ley autonómica, lo que implica una diferenciación de trato evidente.

También existen fuertes diferencias en el caso de las dotaciones al Fondo de Educación y Promoción, (en adelante FEP) como podemos observar en las tablas 4 y 5 del apartado 3. Sin embargo, en el caso de éste, como las dotaciones se realizan, normalmente, con cargo sólo a rendimientos cooperativos, las distorsiones vienen determinadas únicamente por el porcentaje, que oscila entre un 5\% y un 10\%. Efectivamente, sólo Andalucía contempla la posibilidad de que el FEP se dote asimismo con cargo a beneficios extracooperativos (que no extraordinarios).

Asimismo, existen algunos casos en que se contempla la dotación a realizar en caso de contabilización conjunta de resultados, que como es sabido, supone la pérdida de la condición de protegida para la cooperativa (D.A. $6^{\text {a }}$ Ley 27/1999). De forma conjunta, podemos resumir los porcentajes en las tablas citadas del apartado 3.

2. "Repartir entre los socios los fondos de reserva que tengan carácter de irrepartibles durante la vida de la sociedad y el activo sobrante en el momento de su liquidación”.

Las diferentes legislaciones deciden qué Fondos son irrepartibles y cuáles no durante la vida de la sociedad. Siempre resulta irrepartible el FEP o sus equivalentes.

En cuanto al Fondo de Reserva Obligatorio, en adelante FRO, es normalmente irrepartible, pero existen excepciones. Cabe destacar que las legislaciones andaluza (Ley de Sociedades Cooperativas Andaluzas, 2/1999, de 31 de marzo, Artículo 95.2), asturiana (Ley de Cooperativas del Principado de Asturias, 4/2010, de 29 de junio, artículos 100 y 127.2.c), manchega (Ley de Cooperativa de Castilla-La Mancha 2010, Ley 11/2010, de 4 de noviembre, Artículo 90.1) y murciana (Ley de Sociedades Cooperativas de Murcia, Ley 8/2006, de 16 de noviembre, art. 75.1) permiten el reparto, si existe previsión estatutaria del mismo, en casi todos los casos sólo hasta el 50\%. Es totalmente repartible en el caso de las cooperativas especiales extremeñas (art. 13 de la Ley 8/2006, de sociedades cooperativas especiales de Extremadura). Ahora bien, en la medida en que la ley remite a las repartibilidad 
de los Fondos que fueran irrepartibles, en el caso de las cooperativas sometidas a estas leyes, el reparto no supondrá pérdida de la condición de protegida, generando, una vez más, diferencias de trato notables5.

En cuanto al activo sobrante en el momento de la liquidación, la LFC no remite a lo que disponga la legislación cooperativa, sino que castiga directamente dicho reparto, con la pérdida de la condición de protegida. El precepto plantea por ello dos problemas, en nuestra opinión:

El primero, la interpretación del concepto de "activo sobrante". En el momento de la redacción de la LFC, la definición del mismo se desprendía con bastante claridad del tenor de la ley 3/1987, de 2 de abril, General de Cooperativas. En efecto, en el art. 112 de aquella norma se establecía la repartibilidad a los socios únicamente de las aportaciones al capital social, teniendo el resto del haber social un destino desinteresado ${ }^{6}$. Algunas de las leyes autonómicas lo siguen regulando así ${ }^{7}$. Sin embargo, muchas leyes posteriores, tanto la estatal como la mayoría de las autonómicas, han considerado repartibles también las reservas voluntarias repartibles, distintas de los Fondos obligatorios irrepartibles ${ }^{8}$. Por otra parte, adicionalmente, las leyes que preveían el reparto, aun parcial, del FRO durante la vida de la sociedad, también lo contemplan, de forma coherente, en el momento de su liquidación ${ }^{9}$. Y por último, en algunas leyes se prevé expresamente el reparto del haber social sobrante tras la liquidación, como en las cooperativas especiales extremeñas ${ }^{10}$, o en las de segundo grado

\footnotetext{
${ }^{5}$ En el caso de dicho reparto, el tratamiento para el socio será de rendimientos de capital mobiliario, según la DGT en Resolución núm. 424/2002 de 13 marzo (JUR\2002\175393).

6 Así, en su apartado 4 establecía: "El activo sobrante, si lo hubiere así como el remanente existente del Fondo de Educación y Promoción, se pondrá a disposición del Consejo Superior del Cooperativismo, que deberá destinarlo, de modo exclusivo, a la promoción del cooperativismo".

${ }^{7}$ Por ejemplo, así lo dispone el art. 105 de la ley extremeña, 2/1998, de 26 de marzo.

${ }^{8}$ Así lo prevén el Artículo 89 de la Ley estatal de cooperativas, 27/1999, de 16 de julio; el art. 69 Ley de Cooperativas de Aragón, Ley 9/1998, de 22 de diciembre, la Ley de Cooperativas del Principado de Asturias, (Ley 4/2010, de 29 de junio), en su artículo 127. También la Ley de Cooperativas de las Illes Balears (Ley 1/2003, de 20 de marzo), en su artículo 99. Y en la Ley de cooperativas de Castilla y León, (Ley 4/2002, de 11 de abril), Artículo 94; Ley de Cooperativas de Cataluña 2002, (Ley 18/2002, de 5 de julio) Artículo 8; Ley de Cooperativas de Galicia (Ley 5/1998, de 18 de diciembre), Artículo 93; Ley de Cooperativas de La Rioja (Ley 4/2001, de 2 de julio), artículo 99; Ley de Cooperativas de Madrid (Ley 4/1999, de 30 de marzo), Artículo 101; Ley Foral de Cooperativas de Navarra (14/2006, de 11 de diciembre), artículo 63; Ley de Cooperativas de Comunidad Valenciana (Ley 8/2003, de 24 de marzo), Artículo 71.

${ }^{9}$ Véase la Ley de Cooperativa de Castilla-La Mancha 2010, Ley 11/2010, de 4 de noviembre, artículo 118); y la Ley de Sociedades Cooperativas de Murcia (Ley 8/2006, de 16 de noviembre), artículo 102.

${ }^{10}$ Así, el reparto del haber sobrante tras la liquidación se prevé para las cooperativas especiales extremeñas (art. 15 Ley 8/2006, de 23 de Diciembre, de Sociedades Cooperativas Especiales de Extremadura), así como el Fondo de reserva irrepartible (art. 13).
} 
también extremeñas ${ }^{11}$. Por lo tanto, no es fácil determinar qué activo sobrante es el que no debe repartirse.

El segundo lo constituye la propia aplicación de la causa de pérdida de la condición de protegida, ya que la circunstancia ocurre precisamente cuando la cooperativa cesa en su actividad y, por tanto, deja de tributar por este impuesto. Efectivamente, según el art. 37 de la LFC, la pérdida del régimen se producirá en el ejercicio económico en que se produzca, con lo que la cooperativa tributaría en régimen general sólo en su último ejercicio social, cuando se acordara la liquidación. En este caso podría aplicarse la responsabilidad subsidiaria de los liquidadores prevista en la Ley General Tributaria (Busquets, 2005). Una posible interpretación, que ofrecería una vigencia mayor al precepto, sería que en el caso de que los Estatutos prevean dicho reparto, la cooperativa no pudiera considerarse fiscalmente protegida.

3. "Aplicar cantidades del fondo de educación y promoción a finalidades distintas de las previstas por la Ley”.

En todas las legislaciones existe unanimidad en la obligación de dotarlo, como hemos visto, y se establecen unos usos bastantes similares. Debe tenerse en cuenta que, en caso de que se aplique el FRO a finalidades distintas de las aprobadas para el mismo, la cooperativa no sólo pierde la condición de protegida, sino que la cantidad así utilizada se computa como ingreso del ejercicio (art. 19.4 Ley 20/1990) ${ }^{12}$. “Incumplir las normas reguladoras del destino del resultado de la regularización del balance de la cooperativa o de la actualización de las aportaciones de los socios al capital social”.

En todas las legislaciones cooperativas existe una remisión a la norma general correspondiente al destino del resultado de la regularización de balances. Pero seguidamente, se detectan diferencias en relación con el destino de la citada regularización ya que puede destinarse parcialmente a Fondos irrepartibles, o un uso parcial para revalorización de aportaciones o incluso destinarse a fondos repartibles. La más peculiar de las legislaciones es la murciana que los califica de resultados cooperativos (Ley 8/2006, art ${ }^{0}$ 78.1.f: "son resultados cooperativos los que se derivan de la regularización de balances"). Afortunadamente, no ha habido posibilidad de "regularizaciones de balance", que pudieran originar conflictos con la aplicación de la norma fiscal, excepto la del RDL 7/1996, de 7 de

\footnotetext{
${ }^{11}$ Art. 161 de la Ley 2/1998, de 26 de marzo, de Cooperativas de Extremadura.

${ }^{12}$ Es un deber de la cooperativa la demostración de cómo se utilizó el saldo del Fondo, como señala la STSJ Castilla y León, Burgos, nº 113/2006, de 28 de febrero (JUR/2006/118690).
} 
junio, de carácter voluntario y en la que no nos consta un acogimiento importante en el sector cooperativo. También es atípica la legislación manchega permitiendo múltiples destinos a los resultados de la actualización de balances ${ }^{13}$

En relación con el segundo supuesto contemplado en el requisito, sobre el destino de la "actualización de las aportaciones de los socios al capital social", las regulaciones realizadas en la normativa sustantiva son bastante homogéneas. Sin embargo, es importante destacar, que para los casos de disolución de la cooperativa, la mayoría de regímenes permiten el reembolso del capital a los socios "revalorizado", o "actualizado", pero sin mencionar, en ningún caso, con cargo a qué fondo, por lo que se supone que será contra el remanente del "haber social". (P. ej. Ley general 72/1999, art' 75.2.b). Finalmente, también cabe destacar la legislación balear, (Ley 1/2003, $\operatorname{Art}^{\circ}$ 80.2), que de forma muy original permite destinar el $10 \%$ de los resultados cooperativos o extracooperativos a un fondo de devolución de aportaciones.

4. "Retribuir las aportaciones de los socios o asociados al capital social con intereses superiores a los máximos autorizados en las normas legales...”

Las diferentes legislaciones cooperativas fijan una retribución máxima que oscila entre 3 y 6 puntos por encima del interés legal del dinero, siendo la manchega la que establece más de 10 puntos. ( Art $^{\mathrm{o}} 79$ Ley 11/2010) Hay algunas que establecen un porcentaje sobre dicho interés, como la riojana, (Art ${ }^{\circ}$ 64, Ley 4/2001) que fija el límite en hasta un 50\% más que el mismo. Debe tenerse en cuenta que en la misma ley 20/1990, se fija una retribución máxima deducible para la Base imponible en el art. 18.3, que no coincide tampoco con las normativas autonómicas.

5. “Cuando los retornos sociales fueran acreditados a los socios en proporción distinta a las entregas, actividades o servicios realizados con la cooperativa o fuesen distribuidos a terceros no socios".

Todas las leyes de cooperativas obligan al reparto de retornos en proporción a la actividad cooperativizada excepto la madrileña, (Ley 4/1999, $\operatorname{art}^{\circ}$ 60.2.e), que permite el reparto "igualitario". Según la ley de cooperativas "especiales extremeñas" (ley 8/2006, artº 11) que operan como sociedades mercantiles, en éstas tampoco se exige este requisito.

\footnotetext{
${ }^{13}$ Ley $11 / 2010$, art ${ }^{\circ} 80.2$.
} 
Téngase en cuenta que en este caso, la ley 20/1990 no efectúa una remisión a la ley sustantiva, sino que establece la condición directamente, con lo que aunque la ley autonómica lo permita, se perdería la condición de fiscalmente protegida.

Una cuestión bastante relevante que puede plantearse en relación con este requisito es la prohibición que realiza sobre reparto de retornos a terceros no socios. A estos efectos, la mayoría de leyes sustantivas incluyen la opción estatutaria de hacerlo con los trabajadores asociados

6. "No imputar las pérdidas del ejercicio económico o imputarlas vulnerando las normas establecidas en la Ley, los estatutos o los acuerdos de la Asamblea general”.

Todas las legislaciones suelen establecer expresamente el orden en la imputación de pérdidas, siendo bastante diferentes las distintas regulaciones. En la tabla 2 siguiente se describen sumariamente todas, resultando la forma más habitual la de empezar por las reservas voluntarias, si las hay, luego la reserva obligatoria con ciertos límites, y finalmente, imputación al socio de forma proporcional a la actividad cooperativizada. No obstante, algunas permiten compensarse con futuros beneficios, antes de su imputación (Las dos leyes castellanas, Cataluña, Euskadi, Galicia, Rioja, Murcia y la estatal), pero en periodos diferentes, entre 5 y 15 años. En muchos casos las pérdidas de origen extracooperativo se cargan a reservas. (Aragón, Andalucía Madrid y Valencia).

Finalmente es de destacar que por la vía de pérdidas de origen cooperativo, con cargo a la Reserva Obligatoria, se pueden sanear pérdidas, si bien se establecen limitaciones normalmente situadas en el entorno del $50 \%$ o de la media de las dotaciones a la misma durante los 5 últimos años. Las excepciones son Valencia, donde el límite sólo se aplica hasta que la cifra de FRO resulta igual a la de Capital Social; y asimismo Navarra, o Galicia, donde no hay límites.

Tabla 2. Imputación de pérdidas en las distintas leyes cooperativas.

\begin{tabular}{|c|c|c|c|c|c|}
\hline & \multicolumn{4}{|c|}{ IMPUTACION DE PÉRDIDAS } & \\
\hline & $1^{\circ}$ & $2^{\circ}$ & $3^{\circ}$ & $4^{\circ}$ & Legislación \\
\hline ARAGON & $\begin{array}{l}\text { Reservas } \\
\text { voluntarias }\end{array}$ & $\begin{array}{l}\text { Reserva obligatoria } \\
\text { hasta } 50 \% \text { pérdidas. Si } \\
\text { extra coop, } 100 \%\end{array}$ & \begin{tabular}{|l|} 
Resto, a los \\
socios en \\
proporción a su \\
actividad \\
\end{tabular} & & $\begin{array}{l}\text { Art. 58.5 Ley } \\
\text { 9/1998 }\end{array}$ \\
\hline ANDALUCIA & $\begin{array}{l}\text { Reservas } \\
\text { voluntarias }\end{array}$ & $\begin{array}{l}\text { Reserva obligatoria } \\
\text { hasta } 50 \% \text { pérdidas. Si } \\
\text { extra coop, } 100 \%\end{array}$ & $\begin{array}{l}\text { Resto, a los } \\
\text { socios en } \\
\text { proporción a su }\end{array}$ & & $\begin{array}{l}\text { Art..94. Ley } \\
\text { 2/1999 }\end{array}$ \\
\hline
\end{tabular}

REVESCO No 110 - Primer Cuatrimestre 2013 - ISSN: 1885-8031 - www.ucm.es/info/revesco 


\begin{tabular}{|c|c|c|c|c|c|}
\hline & & & actividad & & \\
\hline ASTURIAS & $\begin{array}{l}\text { Reservas } \\
\text { voluntarias }\end{array}$ & $\begin{array}{l}\text { Reserva obligatoria } \\
\text { hasta media } 5 \text { últimos } \\
\text { años }\end{array}$ & \begin{tabular}{|l|} 
Resto, a los \\
socios en \\
proporción a su \\
actividad o \\
mínimo \\
obligatorio, si \\
menor \\
\end{tabular} & & $\begin{array}{l}\text { Art. } 99 \text { Ley } \\
4 / 2010\end{array}$ \\
\hline BALEARES & $\begin{array}{l}\text { Reservas } \\
\text { voluntarias o } \\
\text { estatutarias }\end{array}$ & $\begin{array}{l}\text { Reserva obligatoria } \\
\text { hasta media } 5 \text { últimos } \\
\text { años }\end{array}$ & \begin{tabular}{|l|} 
Resto, a los \\
socios en \\
proporción a su \\
actividad \\
\end{tabular} & & $\begin{array}{l}\text { art. 81 Ley } \\
1 / 2003\end{array}$ \\
\hline $\begin{array}{l}\text { CASTILLA } \\
\text { LA MANCHA }\end{array}$ & $\begin{array}{l}\text { Cuenta } \\
\text { compensable } \\
\text { en } 10 \text { años }\end{array}$ & $\begin{array}{l}\text { Reservas voluntarias o } \\
\text { estatutarias }\end{array}$ & $\begin{array}{l}\text { Reserva } \\
\text { obligatoria } \\
\text { hasta } 50 \% \\
\text { pérdidas o } \\
\text { media } 5 \\
\text { últimos años } \\
\end{array}$ & $\begin{array}{l}\text { Resto, a los } \\
\text { socios en } \\
\text { proporción a su } \\
\text { actividad } \\
\end{array}$ & $\begin{array}{l}\text { art. 89 Ley } \\
11 / 2010\end{array}$ \\
\hline $\begin{array}{l}\text { CASTILLA } \\
\text { LEON }\end{array}$ & $\begin{array}{l}\text { Cuenta } \\
\text { compensable } \\
\text { en } 7 \text { años }\end{array}$ & Reservas voluntarias & $\begin{array}{l}\text { Reserva } \\
\text { obligatoria } \\
\text { hasta } 50 \% \text { de } \\
\text { las pérdidas }\end{array}$ & $\begin{array}{l}\text { Resto, a los } \\
\text { socios en } \\
\text { proporción a su } \\
\text { actividad }\end{array}$ & $\begin{array}{l}\text { art. } 75 \text { Ley } \\
4 / 2002\end{array}$ \\
\hline CATALUÑA & $\begin{array}{l}\text { Cuenta } \\
\text { compensable } \\
\text { según años } \\
\text { del Impto. } \\
\text { s/Sociedades }\end{array}$ & Reservas voluntarias & $\begin{array}{l}\text { Reserva } \\
\text { obligatoria } \\
\text { hasta } 50 \% \text { de } \\
\text { las pérdidas. } \\
\text { No hacer } \\
\text { retornos hasta } \\
\text { compensar este } \\
\text { uso } \\
\end{array}$ & $\begin{array}{l}\text { Resto, a los } \\
\text { socios en } \\
\text { proporción a su } \\
\text { actividad } \\
\end{array}$ & $\begin{array}{l}\text { Art. } 67 \text { Ley } \\
18 / 2002\end{array}$ \\
\hline EUSKADI & $\begin{array}{l}\text { Cuenta } \\
\text { compensable } \\
\text { en } 5 \text { años }\end{array}$ & Reservas voluntarias & $\begin{array}{l}\text { Reserva } \\
\text { obligatoria } \\
\text { hasta media } 5 \\
\text { últimos años }\end{array}$ & $\begin{array}{l}\text { Resto, a los } \\
\text { socios en } \\
\text { proporción a su } \\
\text { actividad } \\
\end{array}$ & Ley 4/1993 \\
\hline $\begin{array}{l}\text { EXTREMADU } \\
\text { RA }\end{array}$ & $\begin{array}{l}\text { A reserva } \\
\text { obligatoria } \\
100 \% \text { de } \\
\text { Extracoop. }\end{array}$ & $\begin{array}{l}\text { El } 30 \% \text { de coop a } \\
\text { Reserva voluntaria u } \\
\text { obligatoria }\end{array}$ & $\begin{array}{l}\text { Resto, a los } \\
\text { socios en } \\
\text { proporción a su } \\
\text { actividad }\end{array}$ & $\begin{array}{l}\text { Si no existe } \\
\text { suficiente R. } \\
\text { Obligatoria: } \\
\text { cta. } \\
\text { compensatoria } \\
\end{array}$ & $\begin{array}{l}\text { art. 62 Ley } \\
\text { 2/1998 }\end{array}$ \\
\hline GALICIA & $\begin{array}{l}\text { Cuenta } \\
\text { compensable } \\
\text { en } 7 \text { años }\end{array}$ & Reserva obligatoria & $\begin{array}{l}\text { Reservas } \\
\text { voluntarias }\end{array}$ & $\begin{array}{l}\text { Resto, a los } \\
\text { socios en } \\
\text { proporción a su } \\
\text { actividad }\end{array}$ & $\begin{array}{l}\text { Art. } 69 \text { ley } \\
5 / 1998\end{array}$ \\
\hline LA RIOJA & $\begin{array}{l}\text { Cuenta } \\
\text { compensable } \\
\text { en } 7 \text { años }\end{array}$ & Reservas voluntarias & $\begin{array}{l}\text { Reserva } \\
\text { obligatoria } \\
\text { hasta } 50 \% \text { de } \\
\text { las pérdidas }\end{array}$ & $\begin{array}{l}\text { Resto, a los } \\
\text { socios en } \\
\text { proporción a su } \\
\text { actividad o } \\
\text { mínimo } \\
\text { obligatorio, si } \\
\text { menor }\end{array}$ & $\begin{array}{l}\text { art. } 73 \text { Ley } \\
4 / 2001\end{array}$ \\
\hline $\begin{array}{l}\text { MADRID } \\
\text { cooperativos }\end{array}$ & $\begin{array}{l}\text { Reservas } \\
\text { voluntarias }\end{array}$ & $\begin{array}{l}\text { Reserva obligatoria } \\
\text { hasta } 50 \% \text { pérdidas o } \\
\text { media } 5 \text { últimos años }\end{array}$ & $\begin{array}{l}\text { Resto, a los } \\
\text { socios en } \\
\text { proporción a su } \\
\text { actividad o } \\
\text { mínimo }\end{array}$ & & $\begin{array}{l}\text { Art. } 61 \text { Ley } \\
4 / 1999\end{array}$ \\
\hline
\end{tabular}




\begin{tabular}{|c|c|c|c|c|c|}
\hline & & & $\begin{array}{l}\text { obligatorio, si } \\
\text { menor }\end{array}$ & & \\
\hline $\begin{array}{l}\text { MADRID } \\
\text { extracooperativ } \\
\text { os }\end{array}$ & $\begin{array}{l}\text { Reserva } \\
\text { obligatoria o } \\
\text { voluntaria }\end{array}$ & $\begin{array}{l}\text { Cuenta compensable en } \\
7 \text { años }\end{array}$ & $\begin{array}{l}\text { A los socios en } \\
\text { proporción al } \\
\text { capital }\end{array}$ & & $\begin{array}{l}\text { Art. } 61 \text { Ley } \\
4 / 1999\end{array}$ \\
\hline MURCIA & $\begin{array}{l}\text { Cuenta } \\
\text { compensable } \\
\text { en } 7 \text { años }\end{array}$ & Reservas voluntarias & $\begin{array}{l}\text { Reserva } \\
\text { obligatoria } \\
\text { hasta media } 5 \\
\text { últimos años }\end{array}$ & $\begin{array}{l}\text { Resto, a los } \\
\text { socios en } \\
\text { proporción a su } \\
\text { actividad }\end{array}$ & $\begin{array}{l}\text { Art. 81 Ley } \\
7 / 2006\end{array}$ \\
\hline NAVARRA & Reservas ó & $\begin{array}{l}\text { ó a los socios en } \\
\text { proporción a su } \\
\text { actividad }\end{array}$ & & & $\begin{array}{l}\text { art. 53 Ley Foral } \\
14 / 2006\end{array}$ \\
\hline $\begin{array}{l}\text { C. } \\
\text { VALENCIAN } \\
\text { A }\end{array}$ & $\begin{array}{l}\text { Reservas } \\
\text { voluntarias }\end{array}$ & $\begin{array}{l}\text { Reserva obligatoria } \\
\text { hasta dejarla igual al } \\
\text { capital social. Si extra } \\
\text { coop, } 100 \%\end{array}$ & $\begin{array}{l}\text { Resto, a los } \\
\text { socios en } \\
\text { proporción a su } \\
\text { actividad o } \\
\text { mínimo } \\
\text { obligatorio, si } \\
\text { menor } \\
\end{array}$ & & $\begin{array}{l}\text { Art. } 69 \text { Ley } \\
8 / 2003\end{array}$ \\
\hline $\begin{array}{l}\text { LEY } \\
\text { ESTATAL }\end{array}$ & $\begin{array}{l}\text { Cuenta } \\
\text { compensable } \\
\text { en } 7 \text { años }\end{array}$ & Reservas voluntarias & $\begin{array}{l}\text { Reserva } \\
\text { obligatoria } \\
\text { hasta media } 5 \\
\text { últimos años }\end{array}$ & $\begin{array}{l}\text { Resto, a los } \\
\text { socios en } \\
\text { proporción a su } \\
\text { actividad }\end{array}$ & $\begin{array}{l}\text { art. 59 Ley } \\
27 / 1999\end{array}$ \\
\hline
\end{tabular}

Fuente: Elaboración propia

7. "Cuando las aportaciones al capital social de los socios o asociados excedan los límites legales autorizados".

En las distintas leyes cooperativas, la concentración de capital máximo en un solo socio oscila entre el $33 \%$ y el 50\%, no pareciendo que existan problemas de aplicación. El límite más alto está en la legislación manchega, lo cual es lógico, ya que con sólo dos socios se puede constituir una cooperativa (Art. 74.2 ley 11/2010). También el límite es del 50\% en la legislación de "cooperativas especiales" extremeña (ley 8/2006), lo que es coherente con su status semi-mercantil, que impide su calificación de protegida por varias causas, como se comentó en referencia a los requisitos de los puntos 13.2, 13.3 y 13.6.

8. "Participación de la cooperativa, en cuantía superior al $10 \%$, en el capital social de entidades no cooperativas. No obstante, dicha participación podrá alcanzar el $40 \%$ cuando se trate de entidades que realicen actividades preparatorias, complementarias o subordinadas a las de la propia cooperativa. 
El conjunto de estas participaciones no podrá superar el $50 \%$ de los recursos propios de la cooperativa..."

Ninguna legislación establece esta limitación en el capital social de otras entidades, que constituye, por tanto, un requisito meramente fiscal, establecido con intención de evitar el fraude de ley (De Luis, 1996c) y (Rodrigo, 1998) A lo sumo, aparecen calificados como rendimientos cooperativos los derivados de estas participaciones, si lo son en actividades preparatorias, complementarias o subordinadas, cuando el artículo 21.2 de la LFC los clasifica siempre como extracooperativos, generándose una diferencia de criterio permanente.

Una de las cuestiones que más problemas plantea es la de qué actividades pueden considerarse preparatorias, complementarias o subordinadas a las de la cooperativa. La Administración suele referirla al fin típico de la cooperativa (Soto, 2007). Se prevé la posible autorización por el Ministerio de Hacienda de participaciones superiores ${ }^{14}$, si bien sólo para el caso de actividades subordinadas, complementarias, etc.,

9. "La realización de operaciones cooperativizadas con terceros no socios, fuera de los casos permitidos en las Leyes, así como el incumplimiento de las normas sobre contabilización separada de tales operaciones y destino al Fondo de Reserva Obligatorio de los resultados obtenidos en su realización. Ninguna cooperativa, cualquiera que sea su clase, podrá realizar un volumen de operaciones con terceros no socios superior al $50 \%$ del total de las de la cooperativa, sin perder la condición de cooperativa fiscalmente protegida....”.

Se establecen, pues, tres mandatos: 1) No realizar más operaciones con terceros que las previstas en las leyes cooperativas; 2) No superar en ningún caso - aunque la normativa sustantiva lo permita - el límite del 50\% del total de operaciones; 3) cumplir las obligaciones establecidas en la normativa cooperativa respecto a que los rendimientos derivados de estas operaciones se contabilicen separadamente y se destinen al FRO.

\footnotetext{
${ }^{14}$ En general, vid. Dirección General de Tributos, Resolución núm. 1411/1998 de 31 julio (JURL20011215651). Así se ha considerado por la DGT la participación en un $100 \%$ de una cooperativa de trabajo asociado en una empresa de inserción socio-laboral, en la Resolución núm. 1160/2007 de 5 junio (JURl20071246164). En general, según dicho organismo, encargado de emitir las autorizaciones , por delegación efectuada por Orden del Ministerio de Economía y Hacienda de 18 de noviembre de 1999. Para obtener la autorización ha de tratarse de participaciones en sociedades que redunden en beneficio de los socios cooperativistas, que no desarrollen actividades concurrentes con la cooperativa y que contribuyan a alcanzar los fines de ésta (Res. DGT 28 de abril de 2000.)
} 
En cuanto a los dos primeros, no existe ninguna limitación "genérica" en las diferentes legislaciones (Vargas y Aguilar, 2004), sino que las limitaciones a las operaciones con terceros se contemplan en la regulación específica para cada tipo de cooperativas (agrarias, consumo, etc...). El problema que plantea esta regulación es la definición de "operaciones cooperativizadas", concepto de no aparece explicado en la LFC, salvo que podamos considerar tal la referencia del artículo 15 de la ley, que regula su valoración como aquellas "realizadas por las cooperativas con sus socios, en el desarrollo de sus fines sociales", lo que no aclara, por otro lado si se refiere al objeto social o a cualquier actividad económica de la cooperativa, o sólo a aquella que la define en el tipo cooperativo (trabajo en las de trabajo, consumo en las de consumo). Tampoco se define el concepto de “operaciones con terceros”, por contraposición a "operaciones con socios", salvo en lo relativo a su inclusión en los rendimientos extracooperativos (art. 21). ${ }^{15}$.

Como consecuencia de dicha laguna, el cumplimiento de este requisito podría depender de la dicción de la ley autonómica de aplicación a la cooperativa, pudiendo generarse diferencias importantes ${ }^{16}$..

Por cuanto hace referencia a esta necesidad de contabilización separada, el art. 13 de la LFC remite al cumplimiento de la obligación establecida en la normativa sustantiva, por lo que sólo si ésta lo contempla se incumpliría el requisito. En este sentido, tanto la ley estatal como algunas autonómicas - aunque la ley catalana, por ejemplo, elude hacerlo - contemplan la posibilidad de contabilización conjunta de resultados cooperativos y extracooperativos

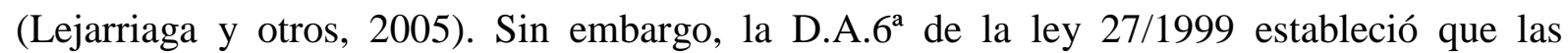
cooperativas que no separaran resultados (incluso si su normativa lo permitía) perderían la condición de fiscalmente protegidas. La mayoría de legislaciones advierten de esta situación si permiten la opción de la contabilización conjunta.

En cuanto al destino de dichos rendimientos al FRO, ya hemos visto en relación con el apartado primero de este precepto que no todas las legislaciones cooperativas contemplan la

\footnotetext{
${ }^{15}$ La DGT se ha pronunciado en el sentido de que deben considerarse terceros, para una cooperativa de segundo grado, los socios de las de primer grado. Resolución núm. 1354/1998 de 21 julio (JUR\20011217999)

${ }^{16} \mathrm{Sin}$ embargo, en relación con las cooperativas de trabajo asociado, el Tribunal Superior de Justicia de Murcia, en varias sentencias, considera que, a pesar de que en la ley autonómica los rendimientos derivados del trabajo asalariado no se consideraran extracooperativos, a efectos del cumplimiento del requisito aquí señalado, “...la existencia de trabajadores asalariados determina la realización de operaciones cooperativizadas con terceros no socios..." e impone, por tanto, la necesidad de contabilización separada, aunque dichas operaciones no alcancen el 50\% del total de las de la cooperativa. Por todas, vid STSJ Murcia nº 73/2010 de 27 de enero (JT/2010/290) y Sentencia núm. 569/2009 de 29 junio (JUR\2009\308276).
} 
necesidad de que el 100\% de los mismos tengan dicho destino. Por lo tanto, el requisito aquí será distinto para las cooperativas sometidas a leyes cooperativas diferentes. En efecto, los rendimientos derivados de operaciones con terceros se suelen destinar a Fondos irrepartibles, normalmente al FRO y alguna vez, parcialmente, al FEP (Ley Andaluza, art ${ }^{\circ}$ 92, y por contabilización conjunta la Ley vasca, $\operatorname{art}^{\circ} 57$ y la Madrileña $\operatorname{art}^{\circ} 59$ y 60). La regulación más opuesta al espíritu de este requisito puede encontrarse la legislación murciana, que permite operar con terceros hasta el límite que marquen los Estatutos ${ }^{17}$ y destinar los resultados así obtenidos obligatoriamente sólo en un 50\% al FRO, y el resto "según estatutos", o incluso expresamente a "retornos cooperativos" ( $\operatorname{art}^{\mathrm{o}} 80.2$ y 80.3). También la legislación de Castilla -la Mancha (Ley 11/2010, Art $^{\circ} 88.3$ y 88.4) únicamente obliga a dotar el $20 \%$ al FRO de los resultados de las operaciones con terceros "y el resto conforme establezcan los estatutos o acuerde la Asamblea general en cada ejercicio, a retorno cooperativo a los socios, a dotación a fondos de reserva voluntarios, al Fondo de Reembolso, o a incrementar los fondos obligatorios". Finalmente recordar la legislación balear, (ley 1/2003, $\operatorname{Art}^{\circ} 80.2$ ), que permite destinar el 10\% de los resultados extracooperativos a un fondo de devolución de aportaciones, como se comentó en el punto 13.4.

10. "Al empleo de trabajadores asalariados en número superior al autorizado en las normas legales por aquellas cooperativas respecto de las cuales exista tal limitación”.

No existe una limitación "genérica" como ésta en ninguna legislación, aunque si que existe para cooperativas de trabajo asociado o explotación comunitaria de la tierra. A continuación, en la tabla 3, se exponen los diferentes límites de las legislaciones para las de trabajo asociado. Destaca la mayor tolerancia de Extremadura y la menor de Euskadi y Comunidad Valenciana.

Debe tenerse en cuenta que las referencias son diferentes ya que se utilizan distintos criterios: bien las horas anuales trabajadas o el total de socios de la cooperativa.

\footnotetext{
${ }^{17}$ Ley $8 / 2006\left(\operatorname{art}{ }^{\circ} 6\right)$.
} 
Tabla 3. Límites a trabajadores no socios en cooperativas de trabajo asociado.

\begin{tabular}{|c|c|c|c|c|}
\hline CCAA & Porcentaje & Relación & Artículo & Ley CCAA \\
\hline ANDALUCIA & $30 \%$ & $\begin{array}{c}\text { Jornadas } \\
\text { legales/año }\end{array}$ & 126,1 & L 2/1999 \\
\hline ARAGON & $35 \%$ & horas/año & 72,4 & L 9/1998 \\
\hline ASTURIAS & $30 \%$ & horas/año & 151,1 & $\mathrm{~L} 4 / 2010$ \\
\hline BALEARES & $30 \%$ & horas/año & 102,6 & L $1 / 2003$ \\
\hline CASTILLA LA MANCHA & $30 \%$ & horas/año & 123,1 & L $11 / 2010$ \\
\hline \begin{tabular}{|l} 
CASTILLA LEON \\
\end{tabular} & $30 \%$ & horas/año & 100,5 & L 4/2004 \\
\hline CATALUÑA & $30 \%$ & horas/año & 115 & L $18 / 2002$ \\
\hline EUSKADI & $25 \%$ & horas/año & 99,4 & $\mathrm{~L} 1 / 2000$ \\
\hline EXTREMADURA & $40 \%$ & total de socios & 113,9 & L 2/1998 \\
\hline GALICIA & $30 \%$ & total de socios & 110,1 & L 5/1998 \\
\hline LA RIOJA & $30 \%$ & horas/año & 110,1 & $\mathrm{~L} 4 / 2001$ \\
\hline MADRID & $30 \%$ & horas/año & 106,1 & L 4/1999 \\
\hline MURCIA & $30 \%$ & total de socios & 104,6 & $\mathrm{~L} 7 / 2006$ \\
\hline NAVARRA & $30 \%$ & $\begin{array}{c}\text { jornadas } \\
\text { legales/año }\end{array}$ & 67,2 & LF $14 / 2006$ \\
\hline C. VALENCIANA & $10 \%$ & total de socios & 89,4 & L $8 / 2003$ \\
\hline LEY ESTATAL & $30 \%$ & horas/año & 80,7 & L 27/1999 \\
\hline
\end{tabular}

Fuente: Elaboración propia

11. "La existencia de un número de socios inferior al previsto en las normas legales, sin que se restablezca en un plazo de seis meses.”

El número mínimo de trabajadores oscila entre 2 (para microcooperativas o para trabajo asociado) o para cantidades mayores en otros sectores como consumo. Por lo general se remite a 3 ó 4 socios, y está prevista esta circunstancia en todas las legislaciones que esta situación conduzca a la disolución de la cooperativa. Sobre el tema se ha pronunciado la DGT en Resolución núm. 2083/2008 de 6 noviembre (JUR\2009\24521).

12. "La reducción del capital social a una cantidad inferior a la cifra mínima establecida estatutariamente, sin que se restablezca en el plazo de seis meses".

13. “La paralización de la actividad cooperativizada o la inactividad de los órganos sociales durante dos años, sin causa justificada"

14. "La conclusión de la empresa que constituye su objeto o la imposibilidad manifiesta de desarrollar la actividad cooperativizada". 
15. "La falta de auditoría externa en los casos señalados en las normas legales".

Estas circunstancias 13-16 están previstas en todas las legislaciones como causa de disolución de la cooperativa. Excepto en la navarra, (Ley 14/2066, art. 60), en que no se contempla la paralización de la actividad como tal, si bien les es de aplicación una norma fiscal propia (Ley Foral 9/1994, de 21 de junio) y no la ley 20/1990.

\section{DIVERGENCIAS TERRITORIALES EN LOS REQUISITOS PARA SER COOPERATIVA PROTEGIDA}

Cada cooperativa opta en sus Estatutos por una distribución de sus excedentes dentro de los parámetros de su ley sustantiva, escogiendo un porcentaje mínimo para dotar el FEP y el FRO. Pero, debe tenerse muy presente que esta opción redundará en una mayor o presión fiscal, según los porcentajes que escoja, y según que su ley sustantiva obligue a hacer los cálculos del destino del excedente antes o después de impuestos, lo que otorga opciones de planificación fiscal (Romero y Seguí, 2006).

En consecuencia, tenemos que subrayar que es cada ley sustantiva, obligando a un porcentaje mínimo de dotación, quien está fijando la presión fiscal de las cooperativas que regula. Porque la LFC, hace perder la especial protección ( $\left.\operatorname{Art}^{\circ} 13.1\right)$ a quien no efectúe las dotaciones en la cuantía exigida en las disposiciones cooperativas. Es decir, remite a la legislación sustantiva.

Pero, a estos efectos, todavía son más importantes las remisiones a las leyes sustantivas del $\mathrm{Art}^{\circ}$ 18.2, que hace deducibles las dotaciones "obligatorias" al FEP y del $\mathrm{Art}^{\circ}$ 16.5, minora el 50\% de los resultados que se destinen "obligatoriamente" al FRO.

La “obligatoriedad" contenida en estos artículos de la LFC, no está referida al mínimo de la Ley, sino a la referencia estatutaria, aunque no asamblearia, según resolución del TEAC, $\mathrm{n}^{\mathrm{o}} 00 / 7071 / 2000$ de 16/04/2004.

Pero para un análisis comprable de las consecuencias de estas remisiones, nos hemos de basar en los mínimos legales, ya que cualquier otro estudio viene interferido por deducciones o/y bonificaciones, además de las "casi infinitas" combinaciones de opción estatutaria de cada cooperativa. Los resultados de estas remisiones se exponen en las tablas 4 y 5, aplicadas a cooperativas con "protección simple", una para excedente cooperativo y otra para extracooperativo, donde se exponen los mínimos de cada legislación y la forma de 
cálculo, exponiendo a continuación la presión fiscal efectiva, -algunos autores la llaman Tipo Impositivo Efectivo- (Albi y otros, 1988), (Fernández y otros, 2003), (Molina, 2010) como resultado de esa opción mínima legal.

Tabla 4. Discriminación territorial cálculo presión fiscal mínima con resultados cooperativos

\begin{tabular}{|c|c|c|c|c|c|c|c|}
\hline \multirow[t]{2}{*}{ CCAA } & $\begin{array}{l}\text { Dot min } \\
\text { FRO }\end{array}$ & Dot min FEP & $\begin{array}{c}\text { Min } \\
\text { CONJUNTO }\end{array}$ & \multirow[t]{2}{*}{$\begin{array}{c}\text { antes/despues } \\
\text { del IS }\end{array}$} & \multirow[t]{2}{*}{ FRO } & \multirow[t]{2}{*}{$\overline{\text { FEP }}$} & \multirow{2}{*}{$\begin{array}{c}\% \\
\text { PRESION } \\
\text { FISCAL } \\
\text { S/ BAI }\end{array}$} \\
\hline & \multicolumn{2}{|c|}{ DE COOP } & FRO Y FEP & & & & \\
\hline ANDALUCIA (1) & $15-20 \%$ & $5 \%$ & & después & 15 & 5 & 17,949 \\
\hline ARAGON (2) & $10-25 \%$ & $5-20 \%$ & $30 \%$ & después & 25 & 5 & 17,098 \\
\hline ASTURIAS & $20 \%$ & $5 \%$ & & antes & 20 & 5 & 17,000 \\
\hline BALEARES & $20 \%$ & $5 \%$ & & antes & 20 & 5 & 17,000 \\
\hline CASTILLA LA & $5-10 \%$ & $5 \%$ & $15 \%$ & & & & \\
\hline MANCHA(3) & & & & antes & 10 & 5 & 18,000 \\
\hline CASTILLA LEON (4) & $10-20 \%$ & $5 \%$ & & antes & 10 & 5 & 18,000 \\
\hline CATALUÑA & $30 \%$ & $10 \%$ & & antes & 30 & 10 & 15,000 \\
\hline EUSKADI (5) & $20-25 \%$ & $5-10 \%$ & $30 \%$ & después & 25 & 5 & 17,098 \\
\hline EXTREMADURA (6) & $20-30 \%$ & $0-10 \%$ & $30 \%$ & después & 25 & 5 & 17,098 \\
\hline GALICIA (7) & $20-25 \%$ & $5-10 \%$ & $30 \%$ & después & 25 & 5 & 17,098 \\
\hline LA RIOJA (8) & $15-20 \%$ & $5-10 \%$ & $25 \%$ & antes & 20 & 5 & 17,000 \\
\hline MADRID (9) & $20-25 \%$ & $5 \%$ & $25 \%$ & después & 20 & 5 & 17,526 \\
\hline MURCIA & $15 \%$ & $5 \%$ & & antes & 15 & 5 & 17,500 \\
\hline NAVARRA (10) & $10-30 \%$ & $0-10 \%$ & & después & 25 & 5 & 17,098 \\
\hline C. VALENCIANA (11) & $0-20 \%$ & $5 \%$ & & después & 20 & 5 & 17,526 \\
\hline LEY ESTATAL & $20 \%$ & $5 \%$ & $20 \%$ & antes & 20 & 5 & 17,000 \\
\hline
\end{tabular}

Fuente: elaboración propia

(1) Un 20\% hasta que el FRO iguale el 50\% del capital social. Despúes solo el $15 \%$

(2) Un 30\% conjunto al FRO y el FEP. Cuando el FRO iguale el 50\% del C. Social, un 5\% al FEP. Cuando el FRO supere el doble del C. Social, un $10 \%$ al FEP

(3) Un 15\% conjunto al FRO y el FEP, hasta que el FRO iguale el C. Social, con un $10 \%$ al FRO. Superada esta proporción, la cuantía global será del $10 \%$

(4) Un 20\% al FRO y un 5\% al FEP. En el caso de coop. trabajo, explot. comunitaria agraria y enseñanza se deberá destinar, al menos, el 10\% al FRO y un 5\% al FEP

(5) Un 30\% conjunto al FRO y FEP. Mínimo del $20 \%$ al FRO y $10 \%$ al FEP

Hasta que el FRO no alcance el 50\% del Capital Social, al FEP, el 5\%

(6) Un 30\% conjunto al FRO y el FEP. Hasta que el FRO iguale el 50\% del C. Social, un $30 \%$ al FRO.

Cuando el FRO iguale el $50 \%$ del C. Social, un 5\% al FEP y $25 \%$ al FRO

Cuando el FRO supere el doble del C. Social, un $10 \%$ al FEP y un $20 \%$ al FRO

(7) Un 30\% conjunto al FRO y FEP. Mínimo del $20 \%$ al FRO y $5 \%$ al FEP

(8) Un $20 \%$ al FRO y un 5\% al FEP. Si el FRO supera el 50\% del C. Social, $15 \%$ al FRO y un $10 \%$ al FEP

(9) Un 20\% al FRO y un 5\% al FEP. Cuando el FRO triplique el C. Social la Asamblea puede

disminuir el FRO y aumentar el FEP, pero mínimo conjunto del $25 \%$

(10) Un 30\% conjunto al FRO y el FEP. Hasta que el FRO iguale el 50\% del C. Social, un $30 \%$ al FRO.

REVESCO No 110 - Primer Cuatrimestre 2013 - ISSN: 1885-8031 - www.ucm.es/info/revesco 
Cuando el FRO iguale el 50\% del C. Social, un 5\% al FEP y 25\% al FRO

Cuando el FRO supere el doble del C. Social, un $10 \%$ al FEP y un $20 \%$ al FRO. Y en las de $2^{\circ}$ grado.

Cuando el FRO triplique el C. Social, un $10 \%$ al FRO y un $10 \%$ al FEP

(11) Un 20\% al FRO hasta que iguale el capital Social. Luego nada. Siempre un 5\% al FEP

Tabla 5. Discriminación territorial en el cálculo de la presión fiscal mínima con resultados extracooperativos

\begin{tabular}{|c|c|c|c|c|c|c|}
\hline \multirow[t]{2}{*}{ CCAA } & $\begin{array}{l}\text { Dot min } \\
\text { FRO }\end{array}$ & Dot min FEP & \multirow[t]{2}{*}{$\begin{array}{c}\text { antes/despues } \\
\text { del IS }\end{array}$} & \multirow[t]{2}{*}{ FRO } & \multirow[t]{2}{*}{ FEP } & \multirow[t]{2}{*}{ PRESION } \\
\hline & \multicolumn{2}{|c|}{ DE EXTRACOOP } & & & & \\
\hline ANDALUCIA & $80 \%$ & $20 \%$ & después & 80 & 20 & 14,634 \\
\hline ARAGON & $50 \%$ & 0 & después & 50 & 0 & 24,324 \\
\hline ASTURIAS & $50 \%$ & $0 \%$ & antes & 50 & 0 & 22,500 \\
\hline BALEARES (1) & $90-100 \%$ & $0 \%$ & antes & 100 & 0 & 15,000 \\
\hline CASTILLA LA & $20 \%$ & $0 \%$ & & & & \\
\hline $\begin{array}{l}\text { MANCHA } \\
\text { CASTILLA LEON }\end{array}$ & $50 \%$ & $0 \%$ & $\begin{array}{l}\text { antes } \\
\text { antes }\end{array}$ & $\begin{array}{l}20 \\
50\end{array}$ & $\begin{array}{l}0 \\
0\end{array}$ & $\begin{array}{l}27,000 \\
27,500\end{array}$ \\
\hline CATALUÑA & $50 \%$ & $0 \%$ & antes & 50 & 0 & 22,500 \\
\hline EUSKADI (2) & $20-25 \%$ & $5-10 \%$ & después & 25 & 5 & 26,121 \\
\hline EXTREMADURA & $100 \%$ & 0 & después & 100 & 0 & 17,647 \\
\hline GALICIA & $100 \%$ & 0 & después & 100 & 0 & 17,647 \\
\hline LA RIOJA & $50 \%$ & 0 & antes & 50 & 0 & 22,500 \\
\hline MADRID & $100 \%$ & $0 \%$ & después & 100 & 0 & 17,647 \\
\hline MURCIA & $50 \%$ & $0 \%$ & antes & 50 & 0 & 22,500 \\
\hline NAVARRA (3) & $25-50 \%$ & 0 & después & 25 & 0 & 27,273 \\
\hline C. VALENCIANA & $100 \%$ & $0 \%$ & después & 100 & 0 & 17,647 \\
\hline LEY ESTATAL & $50 \%$ & $0 \%$ & antes & 20 & 5 & 25,500 \\
\hline
\end{tabular}

Fuente: Elaboración propia

(1) Un 10\% a un F. Reserva para reembolso de aportaciones, si existe. El resto al FRO

(2) Un $30 \%$ conjunto al FRO y FEP. Mínimo del $20 \%$ al FRO y $10 \%$ al FEP

Hasta que el FRO no alcance el 50\% del Capital Social, al FEP, el 5\%

(3) Un 50\% al FRO. Cuando el FRO triplique el C. Social, un 25\% al FRO.

Como comentarios a las tablas, se puede deducir lo siguiente:

a. En los resultados cooperativos no se observan grandes diferencias en el tipo impositivo efectivo, entre el 17 y el 18\%, ya que la dotación mínima es muy similar. La excepción está en Cataluña, donde la dotación mínima es mayor, y por tanto la presión fiscal menor, un $15 \%$

b. En los extracooperativos, la diferencia es muy relevante, entre el 14.6\% de Andalucía y más del $27 \%$ de Navarra y Castilla La Mancha, por la mayor amplitud de dotaciones obligatorias. En Andalucía se dota el FEP, casi como única excepción; y en el resto se 
dota el FRO al 50 ó 100\%, excepto en las dos comunidades de mayor presión, donde se dota muy poco.

c. Los cálculos de la distribución de los excedentes antes o después de impuesto, que como se puede comprobar corresponde al $50 \%$ para cada opción, respectivamente, tienen una incidencia muy baja en resultados cooperativos: aproximadamente medio punto. Puede comprobarse, para una dotación del 20\% y 5\% para FRO y FEP respectivamente, como efectuando los cálculos antes de impuestos la presión es del $17 \%$ y de $17.56 \%$, si es después. Es un resultado lógico porque antes de impuestos se dota más cantidad a fondos irrepartibles.

d. Los cálculos de la distribución de los excedentes antes o después de impuesto, en resultados extracooperativos es mucho mayor. Puede comprobarse, para una dotación del $50 \%$ y $0 \%$ para FRO y FEP respectivamente, que se produce una diferencia de más 1.8 puntos, y de 2.6 puntos para $100 \%$ y $0 \%$, respectivamente.

e. No es objeto de este artículo el análisis de los inconvenientes prácticos de hacer el cálculo antes de impuesto, pero solo debe reflexionarse qué puede suceder si la base imponible del impuesto es muy grande, por ejemplo, a causa de ajustes extracontables positivos: todo el beneficio antes de impuestos puede resultar una cuota a pagar y no dejar espacio para la dotación a fondos

f. Es pues paradójico que las leyes sustantivas estén provocando importantes divergencias territoriales en la aplicación del Impuesto de sociedades en Cooperativas.

g. Finalmente, deseamos resaltar que este tipo de divergencias territoriales han sido estudiadas en algún artículo, (Molina, 2012) realizando un análisis cuantitativo sobre una muestra de cooperativas muy grande, pero que adolece de la claridad de este análisis. En ese tipo de muestras interfieren en el resultado: a) la opción por una dotación estatutaria -no mínima- de cada cooperativa, b) juntar de forma agregada, tanto a cooperativas sin protección, protegidas y especialmente protegidas, c) no diferenciar en tipo de resultado: -cooperativo y extracooperativo- y, d) las deducciones, bonificaciones y compensaciones de pérdidas aplicadas. No obstante, los resultados del artículo son sorprendentes sobre las diferencias territoriales. 


\section{GRADO DE COINCIDENCIA ENTRE LA REGULACIÓN DE LA LEY 20/1990 Y LAS LEYES COOPERATIVAS}

Veamos la Tabla 6, recapitulativa del grado de coincidencia de la regulación de las distintas leyes sustantivas, en relación con las causas de pérdida de la condición de protegidas contempladas en el art. 13 de la LFC:

Tabla 6. Coincidencia de las distintas leyes cooperativas en relación con las causas de pérdida del

\begin{tabular}{|c|c|c|c|c|c|c|c|c|}
\hline & 13,1 & 13,2 & 13,3 & 13,4 & I & & & \\
\hline & dot FRO y FEP & reparto FR & Uso FEP & act aport CS & retr CS & distr ret & imput pérd & exces CS \\
\hline GENERAL & coincide & coincide & coincide & coincide & máx 6 ptos & coincide & coincide & $\max 1 / 3$ \\
\hline ANDALUCIA & coincide & posible $50 \%$ & \multicolumn{3}{|c|}{ no incompat no incompat máx 3 ptos } & coincide & coincide & $\max 35 \%$ \\
\hline ARAGON & coincide & coincide & coincide & coincide & máx 3 ptos & coincide & coincide & máx $1 / 3$ \\
\hline ASTURIAS & coincide & posible $50 \%$ & coincide & coincide & máx 6 ptos & coincide & coincide & máx $1 / 3$ \\
\hline BALEARES & coincide & coincide & coincide & coincide & máx 3 ptos & coincide & coincide & máx $1 / 3$ \\
\hline \multicolumn{2}{|c|}{ CAST MANCl coincide } & posible & coincide & \multicolumn{2}{|c|}{ no incompat máx 10 ptos } & coincide & coincide & máx $50 \%$ \\
\hline CAST LEON & coincide & coincide & coincide & coincide & máx 6 ptos & coincide & coincide & máx $1 / 3$ \\
\hline CATALUNYA & coincide & coincide & coincide & no regula & máx 6 ptos & coincide & coincide & no regula \\
\hline C. VALENCIA & coincide & posible & coincide & no regula & máx 6 ptos & coincide & coincide & máx 45\% \\
\hline EXTREMADU & coincide & coincide & coincide & coincide & máx 6 ptos & coincide & coincide & máx $1 / 3$ \\
\hline ESP EXTREM & es baja & repartibles & repartibles & no regula & no regula & como merca & \multicolumn{2}{|c|}{ I como mercaı máx 50\% } \\
\hline GALICIA & coincide & coincide & coincide & coincide & máx 3 ptos & coincide & coincide & máx 1/3 \\
\hline RIOJA & coincide & coincide & coincide & coincide & máx $50 \%$ leg & coincide & coincide & máx $1 / 3$ \\
\hline MADRID & coincide & coincide & coincide & coincide & máx 6 ptos & \multicolumn{2}{|c|}{ posib igualit coincide } & máx $45 \%$ \\
\hline MURCIA & coincide & posible $50 \%$ & coincide & resul coop & máx 6 ptos & coincide & coincide & máx $1 / 3$ \\
\hline NAVARRA & coincide & coincide & coincide & coincide & máx 6 ptos & coincide & coincide & máx 33\% \\
\hline EUSKADI & coincide & coincide & coincide & coincide & máx 6 ptos & coincide & coincide & máx $1 / 3$ \\
\hline & 13,9 & 13,10 & 13,11 & 13,12 & 13,13 & 13,14 & 13,15 & 13,16 \\
\hline \multicolumn{3}{|c|}{ partic en otr $>10 \%$ ser con 30: 50} & no trab asal & $\mathrm{n}-$ socios inf & reducc CS & parali activ & \multicolumn{2}{|c|}{ fin objeto soc no audit ex } \\
\hline GENERAL & no dice & no cuantía & no dice & minimo 3 & previsto & previsto & previsto & coincide \\
\hline ANDALUCIA & no dice & no cuantía & no dice & minimo 3 & previsto & previsto & previsto & coincide \\
\hline ARAGON & no dice & no cuantía & no dice & minimo 2 & previsto & previsto & previsto & previsto \\
\hline ASTURIAS & no dice & no cuantía & no dice & mínimo 3 & previsto & previsto & previsto & previsto \\
\hline BALEARES & no dice & no cuantia & no dice & minimo 3 & previsto & previsto & previsto & previsto \\
\hline CAST MANCF & Ino dice & no cuantía & no dice & mínimo 2 & previsto & previsto & previsto & previsto \\
\hline CAST LEON & no dice & no cuantía & no dice & mínimo 3 & previsto & previsto & previsto & previsto \\
\hline CATALUNYA & no dice & no cuantía & no dice & mínimo 3 & previsto & previsto & previsto & previsto \\
\hline C. VALENCIA & Ano dice & no cuantía & no dice & mínimo 3 & previsto & previsto & previsto & previsto \\
\hline EXTREMADU & no dice & no cuantía & no dice & mínimo 3 & previsto & previsto & previsto & previsto \\
\hline ESP EXTREM & no dice & no regula & no dice & mínimo 2 & previsto & previsto & previsto & previsto \\
\hline GALICIA & no dice & no regula & no dice & mínimo 4 & previsto & previsto & previsto & previsto \\
\hline RIOJA & no dice & no regula & no dice & mínimo 3 & previsto & previsto & previsto & previsto \\
\hline MADRID & no dice & no cuantía & no dice & mínimo 3 & previsto & previsto & previsto & previsto \\
\hline MURCIA & no dice & s/estatutos & no dice & mínimo 3 & previsto & previsto & previsto & previsto \\
\hline NAVARRA & no dice & no cuantía & no dice & mínimo 3 & previsto & no previsto & previsto & no regula \\
\hline EUSKADI & no dice & conjunto & no dice & minim 2ó5 & previsto & previsto & previsto & previsto \\
\hline
\end{tabular}

Fuente: elaboración propia 


\section{LOS REQUISITOS PARA SER COOPERATIVA ESPECIALMENTE PROTEGIDA}

En la actualidad, la LFC, en su art. 7, hace una enumeración cerrada de las cooperativas especialmente protegidas, a cuya calificación sólo podrán acceder las de las categorías enumeradas. Estas son:

a) Cooperativas de Trabajo asociado

b) Cooperativas Agrarias

c) Cooperativas de Explotación Comunitaria de la Tierra.

d) Cooperativas del Mar.

e) Cooperativas de Consumidores y usuarios

No se contemplan otras, y no cabe incluir en el concepto de cooperativas de consumidores y usuarios, según la DGT, ni las cooperativas de viviendas ${ }^{18}$, ni las cooperativas de enseñanza ${ }^{19}$. Sin embargo, el TSJ Andalucía, a la vista de la regulación realizada por la ley autonómica, ha considerado que las cooperativas de viviendas andaluzas deben incluirse entre las de consumidores, y por tanto, ser consideradas especialmente $\operatorname{protegidas}^{20}$.

En segundo lugar, además, estas Cooperativas deben cumplir determinados requisitos específicos, que no tienen por qué coincidir con los establecidos en la norma sustantiva para su calificación, para poder acceder a la condición de especialmente protegidas.

Estos requisitos versan, normalmente, y como veremos posteriormente, sobre (De Luis, 1996 c) y (Alonso, 2001):

- Los socios deben ser de una determinada clase (normalmente, coincidente con la naturaleza de la Cooperativa, y sobre todo, personas físicas), lo que excluye la posibilidad, muchas veces de socios sociedades mercantiles, o de otro tipo.

- Se establecen limitaciones a las retribuciones a los socios.

\footnotetext{
${ }^{18}$ Resolución DGT 10 abril 1995.

${ }^{19}$ Consulta Vinculante de la DGT, de 16 de septiembre de 2005.

${ }^{20}$ STSJ Andalucía, Sevilla, de 9 de mayo de 2003.
} 
- También se imponen limitaciones al número de trabajadores asalariados, y/o a las operaciones con terceros, superiores a los de las cooperativas meramente protegidas.

- En ocasiones, se establecen limitaciones al valor del patrimonio de la Cooperativa o de los socios.

Veamos dichos requisitos en concreto, y comparémoslos con los establecidos en la normativa sustantiva para la definición de la concreta categoría de cooperativa:

\subsection{Cooperativas de trabajo asociado}

Los requisitos para la especial protección de estas cooperativas se contemplan en el Artículo 8 de la LFC. Según este precepto, dichas cooperativas deben cumplir con cuatro requisitos que pasamos a comentar:

1. "Que asocien a personas físicas que presten su trabajo personal en la cooperativa para producir en común bienes y servicios para terceros".

Todas las legislaciones, menos la aragonesa, exigen que los socios de las cooperativas de trabajo asociado sean personas físicas. La ley aragonesa (ley 9/1998, $\operatorname{art}^{\circ} 72.1$ ), dice que asociará "principalmente" a personas físicas, pero el 72.3 admite expresamente a las personas jurídicas.

Ahora bien, además de los problemas indicados, en este caso cabría plantearse también si podrían existir socios colaboradores o asociados, según la terminología utilizada por la ley, y seguir siendo cooperativa especialmente protegida. ${ }^{21}$.

2. "Que el importe medio de sus retribuciones totales efectivamente devengadas, incluidos los anticipos y las cantidades exigibles en concepto de retornos cooperativos no excedan del $200 \%$ de la media de las retribuciones normales en el mismo sector de actividad, que hubieran debido percibir si su situación respecto a la cooperativa hubiera sido la de trabajadores por cuenta ajena."

\footnotetext{
${ }^{21}$ (Resolución núm. 1339/2009 de 8 junio, JUR\2009\372897) conservando la calificación de especialmente protegida, y únicamente la de protegida si dichos socios estuvieran contemplados en la normativa cooperativa de aplicación. En cambio, no tiene ninguna relevancia el número de socios de la cooperativa, siempre que se cumpla su normativa sustantiva de aplicación En ese sentido, en referencia a la ley catalana de cooperativas, la DGT en Resolución núm. 1306/2001 de 22 junio (JUR\2002\76326).
} 
Este requisito, que seguramente intenta evitar el reparto de beneficios que no constituyan excedentes, no aparece en ninguna regulación sustantiva, por lo que es un condicionante meramente fiscal. Sí encontramos algo parecido en la legislación italiana ${ }^{22}$.

3. "Que el número de trabajadores asalariados con contrato por tiempo indefinido no exceda del $10 \%$ del total de sus socios. Sin embargo, si el número de socios es inferior a diez, podrá contratarse un trabajador asalariado.

El cálculo de este porcentaje se realizará en función del número de socios y trabajadores asalariados existentes en la cooperativa durante el ejercicio económico, en proporción a su permanencia efectiva en la misma.

La cooperativa podrá emplear trabajadores por cuenta ajena mediante cualquier otra forma de contratación, sin perder su condición de especialmente protegida, siempre que el número de jornadas legales realizadas por estos trabajadores durante el ejercicio económico no supere el $20 \%$ del total de jornadas legales de trabajo realizadas por los socios.

Para el cómputo de estos porcentajes no se tomarán en consideración:

a)Los trabajadores con contrato de trabajo en prácticas, para la formación en el trabajo o bajo cualquier otra fórmula establecida para la inserción laboral de jóvenes.

b)Los socios en situación de suspensión o excedencia y los trabajadores que los sustituyan.

c) Aquellos trabajadores asalariados que una cooperativa deba contratar por tiempo indefinido en cumplimiento de lo dispuesto en el artículo 44 de la Ley 8/1980, de 10 de marzo, del Estatuto de los Trabajadores, (el Estatuto actualmente en vigor es el desarrollado por el Real Decreto legislativo 1/1995, de 24 de marzo) en los casos expresamente autorizados.

d) Los socios en situación de prueba”.

\footnotetext{
22 En el Art 11.3 D.P.R.601/73, se prevé para las cooperativas de trabajo que sea considerado gasto deducible de la base imponible el salario pagado a sus socios hasta el $120 \%$ de los salarios corrientes. El exceso no sería deducible, considerándose como dividendo. Pero si este exceso se incluye en el capital social, sería deducible.
} 
La redacción de este punto utiliza criterios heterogéneos para los límites en la contratación de los trabajadores indefinidos (número de socios) y de éstos más los trabajadores temporales (jornadas legales) así como porcentajes diferentes (10\% y 20\%, respectivamente). En el caso de las jornadas legales, el $20 \%$ se computa sobre el total de las realizadas por los $\operatorname{socios}^{23}$.

La regulación de esta limitación de trabajadores no socios en las cooperativas de trabajo asociado es asimismo muy heterogénea en las diferentes legislaciones sustantivas, que no contemplan tampoco las mismas excepciones en los trabajadores tenidos en cuenta para el cómputo; un ejemplo evidente de diferencia de criterio lo tenemos en la Ley valenciana 8/2003. Art ${ }^{\circ} 89.4$, que exceptúa del cómputo de asalariados e estos efectos a los siguientes:

a)“Quienes renuncien expresamente a ser socios. (:::)

b) Los trabajadores que se incorporen a la cooperativa por subrogación legal, así como los que se incorporen a ella en actividades sometidas a esta subrogación.

c) Los trabajadores contratados para ser puestos a disposición de empresas usuarias cuando la cooperativa actúa como empresa de trabajo temporal.

d) Los discapacitados, salvo para las cooperativas de integración social"

Pero el punto crucial de este requisito está en la proporción de empleados por cuenta ajena en relación con los socios-trabajadores, que se fija en la ley 20/1990 en 20\% de jornadas legales de trabajo. Pues bien, en primer lugar, como hemos visto, no siempre se utiliza este criterio, sino también el de número de trabajadores; pero además, la mayoría de legislaciones exceden este porcentaje, siendo muy frecuente la cifra de 30 ó 35\% de horas o jornales. La más restrictiva es la valenciana, con tan solo un $10 \%$ de horas (Ley 8/2003, art ${ }^{\circ} 89.4$ ) y la más laxa, la extremeña (Ley 2/1998, art $\left.{ }^{\circ} 113.9\right)$ con un 40\% "del total de trabajadores".

Por otra parte, este precepto plantea distorsiones en relación con lo dispuesto en los apartados 10 y 11 del artículo 13 en relación con las operaciones con terceros y el empleo de trabajadores asalariados24. En efecto, no queda claro si para la determinación de estos últimos

\footnotetext{
${ }^{23}$ Véase la Consulta vinculante de la DGT no $1215 / 2007$ de 11 de junio (JT/2007/959).

${ }^{24}$ Por ejemplo, la DGT ha considerado Resolución núm. 1734/2010 de 28 julio (JT\2010\1126) que el artículo 8.3 de la Ley 20/1990 “...no permite excluir de dicho cómputo a los trabajadores que desatiendan la oferta de ingresar como socios en la cooperativa...", a pesar de que la ley de cooperativas de la Comunidad de Madrid, Ley 4/1999, de 30 de marzo, establece en su artículo 106.4 que “...la eventual superación del límite legal a la
} 
conceptos debemos acudir a este artículo 7 o a los preceptos reguladores de carácter sustantivo, que establecen qué se considera tercero o no en las cooperativas de trabajo asociado. Con lo que podemos utilizar criterios distintos para medir las operaciones con terceros en relación con la condición de meramente protegida (lo dispuesto en la normativa sustantiva) y de especialmente protegida (lo establecido en el art. 7).

4. “A efectos fiscales, se asimilará a las cooperativas de trabajo asociado cualquier otra que, conforme a sus estatutos, adopte la forma de trabajo asociado, resultándole de aplicación las disposiciones correspondientes a esta clase de cooperativas”.

No existe ningún conflicto con este requisito, ya que esta redacción es recurrente en las distintas normativas sustantivas, y podría considerarse obvia.

\subsection{Cooperativas agrarias}

En el caso de las Cooperativas agrarias, es el artículo 9 de la Ley 20/90, el que establece los requisitos específicos de éstas. Regula tres, que pasamos a comentar:

1. "Que asocien a personas físicas titulares de explotaciones agrícolas, forestales, ganaderas o mixtas, situadas dentro del ámbito geográfico al que se extienda estatutariamente la actividad de la cooperativa.(... $)^{25, "}$

La totalidad de legislaciones sustantivas permiten asociarse a titulares de explotaciones agrarias, sin determinar la forma jurídica del socio ${ }^{26}$. Este requisito, además, genera serios problemas para el cambio generacional de los socios, así como para el

contratación de trabajadores por cuenta ajena no necesitará autorización administrativa especial, ni tendrá consecuencias desfavorables de ningún tipo para la Cooperativa, siempre que aquel hecho se produzca por causas objetivas y no imputables a la misma." Sin embargo, esta cláusula de la ley podría ser causa suficiente para excluirlos del cómputo de operaciones con terceros que opera en los requisitos del art. 13.10 y 11, y por tanto, podría ser cooperativa meramente protegida.

${ }^{25}$ El precepto continúa: "También podrán ser socios otras cooperativas agrarias y de explotación comunitaria de la tierra protegidas, sociedades agrarias de transformación de las contempladas en el número 3 de la disposición adicional primera de esta Ley, entes públicos, sociedades en cuyo capital social participen mayoritariamente entes públicos y comunidades de bienes y derechos que reúnan las condiciones del párrafo anterior, integradas, exclusivamente, por personas físicas"

${ }^{26}$ Esta necesidad de que todos los socios sean titulares de explotaciones agrarias se pone de manifiesto en la STSJ Castilla y León $n^{\circ}$ 113/2006, de 28 de febrero (JUR/2006/118690), y eliminaría la calificación de especialmente protegida si uno sólo de ellos no lo fuera. Asimismo, el carácter de socio de una sociedad mercantil, por muy pequeña o familiar que sea, les harían perder la especial protección. Así lo ha considerado la DGT en Resolución núm. 1368/1999 de 27 julio (JUR\2001\218080), para una cooperativa agraria que tenía como socio a una sociedad limitada, repitiendo su doctrina ya establecida en una Consulta de 20 de julio de 1999 $\left(n^{\circ} 1368.99\right)$. 
crecimiento de las cooperativas mediante grupos mixtos, y para la realización de acuerdos comerciales con entidades de naturaleza no cooperativa que impliquen participación en el capital.

2. “Que en la realización de sus actividades agrarias respeten los siguientes límites:

a. Que las materias, productos o servicios adquiridos, arrendados, elaborados, producidos, realizados o fabricados por cualquier procedimiento, por la cooperativa, con destino exclusivo para sus propias explotaciones o para las explotaciones de sus socios, no sean cedidos a terceros no socios, salvo que se trate de los remanentes ordinarios de la actividad cooperativa o cuando la cesión sea consecuencia de circunstancias no imputables a la cooperativa.

Las cooperativas agrarias podrán distribuir al por menor productos petrolíferos a terceros no socios con el límite establecido en el apartado 10 del artículo 13 de esta Ley.

b. Que no se conserven, tipifiquen, manipulen, transformen, transporten, distribuyan o comercialicen productos procedentes de otras explotaciones, similares a los de las explotaciones de la cooperativa o de sus socios, en cuantía superior, por cada ejercicio económico, al $5 \%$ del precio de mercado obtenido por los productos propios, o al $40 \%$ del mismo precio, si así lo prevén sus estatutos.

Dicho porcentaje se determinará independientemente para cada uno de los procesos señalados en el presente apartado, en los que la cooperativa utilice productos agrarios de terceros".

En relación con la condición de especialmente protegida, y al igual que ocurría con las cooperativas de trabajo, el art. 9 de la ley 20/1990 establece límites más estrictos para las operaciones con terceros que el art. 13, y que no se remiten a la normativa cooperativa. Así, la cooperativa no podrá realizar con terceros no socios las siguientes operaciones:

a) En relación con la venta de bienes o provisión de servicios realizados por la cooperativa para las explotaciones agrarias, el porcentaje de operaciones permitidas con terceros es cero. Sólo pueden realizarse con terceros las relativas a:

i. Remanentes ordinarios de la actividad cooperativa (concepto que, como se ha señalado, no se define en la ley (Martin y otros, 2006)

ii. Cesiones realizadas por causas no imputables a la cooperativa 
b) En cuanto a la elaboración y distribución de las materias primas aportadas por los agricultores, la cooperativa podrá realizar operaciones con terceros con los siguientes límites:

i. El 5\% del precio de mercado obtenido por los productos de sus socios

ii. El $40 \%$ de dicho precio, si así lo prevén los Estatutos.

Debe tenerse en cuenta que las operaciones que no superen dichos porcentajes o requisitos, no obstante, son consideradas operaciones con terceros a los efectos de la necesidad de contabilización separada de los rendimientos de ellas derivados y, en su caso, de dotación al FRO, siendo susceptibles de generar el incumplimiento del art. 13.10 de la ley, como indica la STS Galicia n 1615/2006, de 26 de octubre (JT/2007/979).

La redacción de este artículo ha tenido algunos cambios en relación a los productos petrolíferos, que finalmente pueden comercializar hasta el $50 \%$ a terceros del total de sus operaciones, según la reciente redacción dada en la Ley 2/2001, de 4 de marzo.

Debe observarse que según la práctica totalidad de legislaciones cooperativas, se permite operar con terceros en las operaciones de comercialización de productos aportados por los socios de hasta el $50 \%$ del total de las operaciones realizadas por la cooperativa (alguacil, $2010 \mathrm{~b}$ ).

Respecto a la actividad de venta de productos o servicios a socios, el parámetro suele ser el mismo, como en la valenciana ( $\operatorname{Art}^{\circ} 87$ ley 8/2003), o la andaluza ( $\operatorname{art}^{\circ}$ 153, Ley 2/1999), extremeña ( $\operatorname{art}^{\circ} 128.2$, ley 2/1998), incluso las más recientes, como la asturiana ( $\operatorname{art}^{\circ}$ 163, Ley 4/2010) o la manchega (Art ${ }^{\circ} 130.10$, Ley 11/2010), que superan el porcentaje de la ley 20/90, y aplican el límite uniforme del 50\%. La excepción está en la madrileña, (Ley 4/1999, art $\left.^{\circ} 109.4\right)$ que coincide con el 40\%, en los dos sentidos de la comercialización, que como vemos, es el máximo contemplado en el régimen fiscal de especial protección para los productos aportados por los socios.

Esta diferencia entre el 40\% (según la LFC) y el 50\% (según la ley sustantiva), en la práctica supone que la cooperativa agraria, aunque su ley lo autorice, no puede superar estos porcentajes so pena de perder la especial protección. Quedan muy lejanos estos límites "de los remanentes ordinarios de actividad" para la actividad de comercialización dirigida a los socios, siendo un potencial foco de incoherencias entre la norma sustantiva y la fiscal. 
3. "Que las bases imponibles del Impuesto sobre Bienes Inmuebles correspondientes a los bienes de naturaleza rústica de cada socio situados en el ámbito geográfico a que se refiere el apartado uno, cuyas producciones se incorporen a la actividad de la cooperativa, no excedan de 95.000 euros, modificándose este importe anualmente según los coeficientes de actualización aplicables al valor catastral de los bienes inmuebles de naturaleza rústica establecidos en la Ley de Presupuestos Generales del Estado. (...)”

Esta redacción también ha sido cambiada recientemente por la ley 2/2011, ya que la anterior hacia perder la protección con un valor catastral muy bajo, y además sin que se previera la actualización anual (Marí, 2011). Es un requisito meramente fiscal, ya que ninguna legislación sustantiva contempla este articulado, por lo que cabe suponer que no se considera que tenga relevancia para la calificación de la cooperativa.

\subsection{Cooperativas del mar}

Remitimos a los comentarios realizados en relación con las cooperativas agrarias.

\subsection{Cooperativas de explotación comunitaria de la tierra}

Remitimos a los comentarios realizados en relación con las agrarias y las de trabajo asociado.

\subsection{Cooperativas de consumidores y usuarios}

Los tres requisitos que deben cumplir estas cooperativas para ser especialmente protegidas se contemplan en el artículo 12 de la Ley 20/1990, y son los siguientes:

1. "Que asocien a personas físicas con el objeto de procurarles, en las mejores condiciones de calidad, información y precio, bienes cuya entrega no esté gravada en el Impuesto sobre el Valor Añadido al tipo incrementado".

Es curioso que se mantenga la dicción sobre el tipo de IVA incrementado, que ya no existe (Martín y otros, 2006). Con respecto de las personas físicas, muy pocas de las legislaciones dicen explícitamente que los consumidores deban ser personas físicas: la madrileña (ley 4/1999, $\operatorname{art}^{\circ}$ 113.1) y la navarra (Ley 14/2006, $\operatorname{art}^{\circ}$ 69). El resto, utiliza fórmulas vagas, o bien expresa que cualquier otra entidad puede ser socia si es la destinataria del consumo o usuaria de los servicios. 
Por lo tanto, quedan fuera de la especial protección las cooperativas que provean de servicios a sus socios (que no sean bienes) y las que tengan socios personas jurídicas. Ninguna de ambas exclusiones puede justificarse fácilmente.

2. "Que la media de las retribuciones totales de los socios de trabajo, incluidos, en su caso, los retornos cooperativos a que tuvieran derecho, no supere el límite establecido en el artículo 8, apartado 2, de esta Ley."

Ninguna normativa cooperativa contempla este requisito para las cooperativas de consumidores y usuarios, por lo que habría que remitirse a las retribuciones de socios de trabajo del artículo 8.2, que como ya hemos comentado es un puro requisito fiscal que no aparece en ninguna legislación sustantiva.

3. "Que las ventas efectuadas a personas no asociadas, dentro del ámbito de las mismas, no excedan del $10 \%$ del total de las realizadas por la cooperativa en cada ejercicio económico o del $50 \%$, si así lo prevén sus estatutos."

El volumen máximo para operaciones con terceros en este tipo de cooperativas es el $50 \%$ en algunas legislaciones: así, la gallega (Ley 5/1998, art $^{\circ} 114$ ) y riojana (ley 4/2001, art $^{\circ}$ 118.2). En el resto, como la general (ley 27/1999, art $^{\circ} 88.2$, ) o andaluza, (ley 2/1999, art $^{\circ}$ 132), no determinan la cuantía, o no regulan este punto concreto, con lo que existe una indeterminación absoluta, que tampoco aclara el artículo 13.10 de la ley 20/90, que utiliza el mismo concepto, si bien impone límites menos duros, como corresponde a su carácter de requisito para la "mera" protección fiscal.

4. "No serán de aplicación las limitaciones del apartado anterior, ni las establecidas en el artículo 13.10, a aquellas cooperativas que tengan un mínimo de 30 socios de trabajo y, al menos, 50 socios de consumo por cada socio de trabajo, cumpliendo respecto de estos con lo establecido en el artículo 8.3."

Este apartado, que enerva la mayoría de requisitos fiscales, no se contempla en ninguna ley sustantiva. Sus efectos son que este tipo de cooperativas puede realizar operaciones con terceros sin límite, sin necesidad de contabilización separada, y, aunque no se trate de una conclusión que se desprenda del texto de la ley, podría interpretarse que todos sus rendimientos se consideran cooperativos a efectos del tipo de gravamen especial. Es, por supuesto, un tratamiento muy excepcional respecto del resto, y que además, no podrán 
aplicarse todas las cooperativas de consumo que cumplan estos requisitos, porque no se lo permitirá alguna de las normativas sustantivas, que establecerán, o bien límites a las operaciones con terceros, o la necesidad de contabilización separada.

\section{EFECTOS DE LOS REQUISITOS PARA SER COOPERATIVA ESPECIALMENTE PROTEGIDA}

Ahora bien, el establecimiento de un listado de cooperativas especialmente protegidas, realizado en función del tipo o categoría de cooperativas, penaliza los siguientes fenómenos:

- la polivalencia, o desarrollo de varias operaciones cooperativizadas, en la medida en que tienen que cumplirse los requisitos de ambas categorías, amén de que ambas (o todas ellas) deben ser consideradas especialmente protegidas ${ }^{27}$, lo que afecta especialmente a las cooperativas integrales (Martín y otros, 2006),

- la creación de cooperativas con objetos sociales innovadores, lo que coarta las posibilidades de crecimiento del sector. Esto es especialmente cierto cuando la cooperativa intenta integrar actividades complementarias y tipos de socios distintos de una misma actividad económica (como clientes y proveedores, por ejemplo),

- las cooperativas que no se encuentran en la lista, a pesar de que puedan ser capaces de generar los mismos beneficios sociales que las que sí están. El caso de las cooperativas de viviendas, o de servicios que no puedan ser consideradas de consumo, es bastante claro.

A nuestro modo de ver, los requisitos específicamente establecidos en las distintas categorías también acarrean algunos efectos perniciosos:

- La determinación de quién pueda ser socio encorseta la posibilidad de captar capital riesgo, y de integrarse en estructuras complejas cooperativas- sociedades mercantiles. Incluso impide la captación de capital a través de asociados o colaboradores. Asimismo, abunda en desincentivar que la cooperativa desarrolle más de una actividad o tenga más de un tipo de socio.

\footnotetext{
${ }^{27}$ En efecto, véase la DGT en Resolución núm. 1967/2004 de 4 noviembre, JUR 2005\4712, acerca de una cooperativa agraria y de consumo, indicando que debería cumplir los requisitos de ambas en la ley 20/1990 para ser considerada especialmente protegida.
} 
- La limitación del patrimonio de la cooperativa o de los socios no parece casar bien con la idea de que la razón de la existencia del régimen es incentivar el cooperativismo. En cambio, sí lo hace con la noción de especial protección a cooperativas pobres o de pequeño tamaño.

- En el caso de la limitación de las operaciones con terceros, la determinación de cuáles sean éstas causa fuertes distorsiones con el requisito contemplado en el art. 13, ya que a diferencia de lo que allí ocurre, no se remite a la normativa sustantiva.

Debemos decir que algunos de estos requisitos sólo pueden entenderse desde la perspectiva de la época en que se redactó la ley, en que por una parte, no se concebían cooperativas fuera de las categorías de la Ley General de Cooperativas, y por otra, se consideran especialmente protegidas a las de pequeño tamaño, poco competitivas, etc. Aun así, consideramos que seguramente, muchos de estos efectos no fueron queridos por el legislador de la LFC, y no fueron previstos en su día (De Luis, 1996 b).

Pues bien, desde nuestro punto de vista, la regulación de los requisitos debería ser más flexible, permitir la innovación en las cooperativas - tanto organizativa, como estructural como de idea de negocio-, evitar problemas interpretativos y el encorsetamiento excesivo de su comportamiento por razones meramente fiscales. Y su fundamento debería ser, no la protección de las cooperativas, sino, como hemos indicado, la simplificación de su régimen técnico y el incentivo de actividades o comportamientos que resultan valiosos desde una perspectiva constitucional y comunitaria.

\section{CONCLUSIONES}

1. Los requisitos para una "protección" contemplados en el artículo 6, referentes al cumplimiento general de la ley sustantiva general tanto incertidumbre jurídica como desigualdades en la administración de la ley, ya que la variedad de regímenes en las distintas legislaciones es muy importante.

2. En relación con los requisitos establecidos para los dos niveles de protección contemplados en la ley, el método seguido es bastante diferente: en el art. 13, para la calificación de protegidas, la ley se remite, en lo general, a lo dispuesto en la ley sustantiva. En cambio, en los arts. 8 a 12, referidos a la especial protección, se suelen establecer condicionantes directos, si bien basados en las características de las categorías de cooperativas 
elegidas en la regulación predominante en la fecha de emisión de la ley: la Ley General de cooperativas de 1987.

3. Las causas de la pérdida de la protección fiscal previstas en la ley son demasiadas, de un lado, y no contemplan aspectos básicos y elementales del concepto de cooperativa, de otro. Asimismo, generan importantes desigualdades de trato, así como contienen verdaderas obsolescencias, amén de que se alejan de la actual regulación sustantiva.

4. Dichas diferencias pueden implicar, incluso, diferencias en el nivel de presión fiscal de las cooperativas dentro de las distintas autonomías, sólo por la configuración en sus respectivas normativas de los elementos relevantes para los requisitos establecidos para el régimen de la LFC.

\section{BIBLIOGRAFIA}

ALBI, E. RODRIGUEZ, J.A. Y RUBIO J.J. (1988) : Nuevas reformas fiscales: una experiencia para España”, Instituto de Estudios Económicos, Madrid. p.p. 314 y ss.

ALGUACIL, M.P. (2001): “Beneficios tributarios de las cooperativas tras la ley estatal 27/1999”. Revista de derecho Financiero y Hacienda pública.

ALGUACIL, M.P. MONTERO, M. ROMERO-CIVERA, A. (2008): "Informe sobre reforma del régimen económico y fiscal de las cooperativas agroalimentarias" CCAE. El documento es accesible en http://www.agro-alimentarias.coop/ficheros/doc/02718.pdf

ALONSO, E. (2001): "Fiscalidad de cooperativas y sociedades laborales". Generalitat de Catalunya, Institut per a la Promoció i la Formació cooperatives.

BUSQUETS, F. (2005): "Responsabilidad tributaria de los socios y de los miembros del Consejo Rector de las Cooperativas”, Sociedad Cooperativa, $n^{\circ}$ 17, p.p. 24-26.

DE LUIS, J. M. (1991): “Jornadas de la ley de régimen fiscal de las cooperativas”, Valencia. Fundescoop, Institut de Promoció i Foment del Cooperativisme, p. p. 33-91.

DE LUIS, J. M (1996): c) "La fiscalidad en las cooperativas", Jornadas sobre Cooperativismo en Castilla y León, 1996, Valladolid.

FERNANDEZ E., MARTINEZ, A. Y GARCIA S. (2003):”La imposición marginal efectiva contable y fiscal como instrumento de adopción de decisiones empresariales”. Documento en línea:

www.asepelt.org/ficheros/File/Anales/2003\%20.../92.PDF

GALLEGO L.P. (2002). "Efectos económicos y fiscales de la legislación sobre sociedades cooperativas en España”, Tesis doctoral inédita, Universidad Politécnica de Valencia. 
JULIÁ J., GALINDO, J.A. Y GALLEGO L.P (1999): "Normativa central y autonómica de la empresa cooperativa en España: Especial referencia a su régimen económico y físcal" REVESCO No 67

LEJARRIAGA G., FERNANDEZ, J. Y ITURRIOZ J. (2005): Estudio sobre la sensibilidad del coste a la contabilización conjunta o separada de los resultados en la sociedad cooperativa. CIRIEC- España, $n^{\circ} 51$

MARTIN, J. MARTIN,F. y RODRIGUEZ, J. (2006): “Cuestiones tributarias y contables de las cooperativas", Iustel.

MOLINA, R. (2012): "La presión fiscal en las cooperativas españolas durante el periodo 2003-2008”. CIRIEC-España nº 74. P.p. 39-58

RODRIGO, M.A. (1998): “Análisis crítico del proyecto de ley de régimen fiscal de cooperativas. Especial referencia a la tributación en el impuesto sobre Sociedades", Jornadas de Cooperativas de Euskadi,

ROMERO-CIVERA A. y SEGUÍ E. (2006): "Implicaciones fiscales en el cálculo del Impuesto de Sociedades tras la nueva Ley valenciana de Cooperativas (8/2003)". CIRIECEspaña $n^{\circ}$ 54, p. 205-230

SOTO, D. (2007): "La participación de las cooperativas en Entidades no cooperativas. Aplicación del régimen fiscal especial", Jurisprudencia tributaria Aranzadi nº 4/2006.

VARGAS, C. Y AGUILAR, M. (2004): "Las operaciones de la cooperativa con terceros y la infundada limitación de las mismas por su tratamiento fiscal privilegiado" REVESCO, Revista de Estudios Cooperativos, $N^{o} 83$, p. 115 - 140. 